\title{
High expression of microRNA-31 and its host gene LOC554202 predict favorable outcomes in patients with colorectal cancer treated with oxaliplatin
}

\author{
YALUN LI ${ }^{1}$, SHIJIE XIN ${ }^{2}$, HUIZHE WU $^{3}$, CHENGZHONG XING $^{1}$, LIREN DUAN $^{2}$, WEIFENG SUN ${ }^{2}$, \\ XIAOYUN HU ${ }^{3}$, RUORAN LIN $^{2}$ and FANGXIAO ZHANG ${ }^{4}$
}

\begin{abstract}
Departments of ${ }^{1}$ Anorectal Surgery and ${ }^{2}$ Vascular Surgery, First Affiliated Hospital of China Medical University, Shenyang, Liaoning 110001; ${ }^{3}$ Department of Pharmacology, School of Pharmacy, China Medical University, Shenyang, Liaoning 110122; ${ }^{4}$ Department of Intensive Care Unit, First Affiliated Hospital of China Medical University, Shenyang, Liaoning 110001, P.R. China
\end{abstract}

Received February 7, 2018; Accepted July 2, 2018

DOI: $10.3892 /$ or.2018.6571

\begin{abstract}
The expression levels of microRNA-31 (miR-31) and LOC554202 have been previously investigated in colorectal cancer (CRC) and their oncogenic and/or tumor suppressive roles have been described. The aim of the present study was to examine the role of miR-31 and its host gene LOC554202 in the prognosis of patients with CRC. Patients with CRC treated with oxaliplatin-based chemotherapy between June 2005 and March 2010 were recruited to the First Affiliated Hospital of China Medical University. Tumor and adjacent mucosal tissues were collected. The detection of miR-31 and/or LOC554202 was performed with probe hybridization targeting. Correlation analysis was performed among the expression levels of miR-31, LOC554202, and their association with clinicopathological parameters and/or survival rates. miR-31 and LOC554202 were expressed at high levels in $\mathrm{CRC}(\mathrm{P}<0.01)$ compared with adjacent intestinal mucosa. A linear correlation was noted for the two markers in CRC tissues $(\mathrm{P}<0.01)$. The expression of miR-31 was significantly higher in adenocarcinoma than in the adjacent intestinal mucosa $(\mathrm{P}<0.01)$, whereas the expression of LOC554202 was significantly higher in the adenocarcinoma and the rectal cancer tissue regions $(\mathrm{P}<0.01)$. The high expression levels of miR-31 and LOC554202 were associated with high disease-free survival (DFS) and overall survival (OS) rates $(\mathrm{P}<0.05)$. Associations between the increase in DFS and OS and the elevated expression levels of miR-31 and LOC554202 were present in patients with colon
\end{abstract}

Correspondence to: Dr Shijie Xin, Department of Vascular Surgery, First Affiliated Hospital of China Medical University, 155 Nanjing North Street, Heping, Shenyang, Liaoning 110001, P.R. China

E-mail: sjxin@cmu.edu.cn

Key words: colorectal cancer, microRNA-31, LOC554202, prognosis, oxaliplatin cancer but not in patients with rectal cancer $(\mathrm{P}<0.05)$. These data indicated that miR-31 and LOC554202 may be potential markers for evaluation of the prognosis of patients treated with oxaliplatin-based chemotherapy.

\section{Introduction}

Colorectal cancer (CRC) is one of the most common types of cancer worldwide, which affects the gastrointestinal tract and is associated with a high mortality rate due to its rapid progression from the initial time period of the diagnosis (1-3). CRC is the fifth leading cause of cancer-associated mortality for men and women in China (4). Although the disease can be successfully treated following an early diagnosis, the majority of patients with CRC present at an advanced pathological stage. Consequently, the survival rate of these patients is considerably low. The identification of novel molecular markers can assist in the early detection of CRC and the prevention of the disease.

MicroRNAs (miRNAs) comprise a class of small, non-coding RNA molecules, 20-22 nucleotides in length, which regulate the post-transcriptional processes of several genes. To date, $\sim 1,000$ miRNAs have been identified that regulate the function of $>50 \%$ of human genes (5). Several miRNAs have elevated expression in human tumors and act in an oncogenic manner, whereas others have reduced expression and act as tumor suppressors $(6,7)$. miRNAs have been identified to possess altered expression in CRC (8). miRNA-31 (miR-31) was shown to be upregulated in BRAF-mutated CRC compared with wild-type CRC, and an association was identified between the expression of miR-31 and proximal tumor location (9). Despite investigations that have been performed in the field of miRNAs and CRC, investigations of changes in the expression levels of miR-31 in different regions of colorectal tissue, and putative associations with other factors involved in the regulation of gene transcription have been limited. The LOC554202 gene, which is located on human chromosome 9, has been shown to possess an intron region responsible for the transcription of miR-31 (10). LOC554202 is transcribed 
into a long non-coding RNA (lncRNA). IncRNAs are a class of RNA sequences abundantly expressed in the nucleus and cytoplasm, which possess $>200$ nucleotides and are involved in the regulation of translation, although they do not possess protein-coding potential (11). IncRNAs can be targeted for tumor diagnosis and/or treatment, suggesting a broad prospect for diagnosis, prognosis, and targeted therapy (12-14). IncRNAs have been found to exist in tumors and are important in their development and progression (15-17). It is important to note that LOC554202 and miR-31 are derived from the same major gene locus, 9p21.3, which indicates that the transcriptional fragment of miR-31 is in the first intron of LOC554202. Both of these sequences share a common promoter. As a consequence, LOC554202 is the host gene of miR-31, and miR-31 is the classic-intron miRNA of LOC554202. Intron miRNAs and their corresponding host genes typically exhibit the same expression profile, indicating that they exert a similar function (18). The expression levels of LOC554202 were found to be upregulated in breast cancer, and the knockdown of this RNA was associated with decreased cellular proliferation and induction of apoptosis, which suggested an oncogenic function (19). The contradictory results of the majority of studies performed on miR-31 and cancer are summarized in Table I. LOC554202 and miR-31 are abnormally expressed in multiple types of tumor, including CRC $(20,21)$. LOC554202 and miR-31 have been shown to be involved in the development and progression of CRC $(20,22,23)$. However, the expression levels of LOC554202 and miR-31 in CRC and their effect on the progression of CRC following oxaliplatin-based chemotherapy remain to be elucidated.

Therefore, the aim of the present study was to examine the expression levels of miR-31 and its host gene LOC554202, and their impact on the overall survival rate of patients with oxaliplatin-treated CRC.

\section{Materials and methods}

Study population. Patients with CRC who received oxaliplatin-based chemotherapy were recruited between June 2005 and March 2010 at the First Affiliated Hospital of China Medical University (Shenyang, China). The inclusion criteria were as follows: i) Initially diagnosed with CRC; ii) tissue specimens were approved for experimental analysis; iii) patients who received oxaliplatin-based FOLFOX and/or XELOX regimens. The principle of chemotherapy is based on the body surface area of the patient and was calculated according to the National Comprehensive Cancer Network (NCCN) guidelines (www.ncen. org). The FOLFOX regimen included $200 \mathrm{mg}$ of oxaliplatin (intravenous infusion) with $600 \mathrm{mg}$ of calcium folinate (intravenous infusion) and $6 \mathrm{~g}$ of fluoride (intravenous infusion $48 \mathrm{~h}$ ). The XELOX regimen included $200 \mathrm{mg}$ of oxaliplatin (intravenous infusion) with capecitabine (oral, 2,000 $\mathrm{mg} / \mathrm{m}^{2}$ body surface area per day, twice orally, 14 days per course). The interval time of the chemotherapy was 21 days. The medication regimen did not significantly change with the NCCN update, thus the medication for all sample patients was considered as an application of the same chemotherapeutic regimen.

The exclusion criteria were as follows: i) Incomplete patient information and/or lack of follow-up; ii) lack of LOC554202 and/or miR-31 detection; iii) loss and/or damage of clinical samples; iv) patients with history of myocardial infarction, cerebral infarction, atrial myxoma, aortic valve regurgitation, pulmonary infarction, renal failure dialysis treatment history, high risk of hypertension, respiratory failure, chronic obstructive pulmonary disease, and/or human immunodeficiency virus; v) serious postoperative complications, including intestinal fistula, anastomotic obstruction and pulmonary infarction; and vi) preoperative adjuvant chemotherapy and/or radiotherapy.

Cancer tissues and the intestinal mucosa were obtained postoperatively. The clinical staging of the patients was performed in accordance with the WHO (World Health Organization) and tumor-node-metastasis staging guidelines (24). The patients included in the present study were phase III, phase IV and/or phase II at high risk. According to the differentiation of the tumor, the patients were classified into Grade 1 (poorly differentiated, medium-poorly differentiated), Grade 2 (medium differentiation), and Grade 3 (medium-well differentiated, well differentiated). All patients underwent enhanced CT examination of pulmonary and abdominal tissue regions prior to surgery. The patients received routine CT scanning and colonoscopy during follow-up in order to detect the metastasis and/or recurrence of the tumor. The tumor adhesion and vascular infiltration were investigated by intraoperative and postoperative pathological examination. The postoperative follow-up duration was 5 years. The average maximum diameter for tumor foci was $\sim 6 \mathrm{~cm}$, which was used as the dividing line of the tumor size.

The present study was approved by the Medical Ethics Committee of the China Medical University at the First Hospital of China Medical University. Written informed consent was required by the patients for their participation in the study, as requested by the ethical guidelines of the First Hospital of China Medical University and the Medical Ethics Committee of the Chinese Medical Universities. All patients were anonymized.

Tissue microarray (TMA). Paraformaldehyde-fixed fresh tissues from the central zone of the medial lobe were embedded in paraffin and sliced into $4-\mu \mathrm{m}$ sections. The sections were stained with hematoxylin and eosin (H\&E) and placed on coverslips with specific mounting medium for observation using an Nikon ECLIPSE 80i microscope (Nikon, Tokyo, Japan). Subsequently, the central zone of tissues was stained, and the paraformaldehyde-fixed tissues were re-organized to a new TMA. A total of six TMAs, comprising three for the cancer tissue and three for the adjacent mucosa, were obtained and sliced into $4-\mu \mathrm{m}$ sections for in situ hybridization (ISH) analysis.

ISH analysis. The ISH was performed as previously described (25). Briefly, the tissues were treated with hydrogen peroxide at room temperature for $10 \mathrm{~min}$. Subsequently, the sections were boiled $\left(95-100^{\circ} \mathrm{C}\right)$ in citric buffer for $15 \mathrm{~min}$ and incubated with protease at $40^{\circ} \mathrm{C}$ for $30 \mathrm{~min}$. The slides were hybridized with the SVV probe in hybridization buffer [6 SSC ( $1 \mathrm{SSC}$ is $0.15 \mathrm{~mol} / 1 \mathrm{NaCl}, 0.015 \mathrm{~mol} / 1 \mathrm{Na}$-citrate), $25 \%$ formamide, $0.2 \%$ lithium dodecyl sulfate, and blocking reagents] at $40^{\circ} \mathrm{C}$ for $2 \mathrm{~h}$. The sequence biotin-digoxin and 
ONCOLOGY REPORTS 40: 1706-1724, 2018

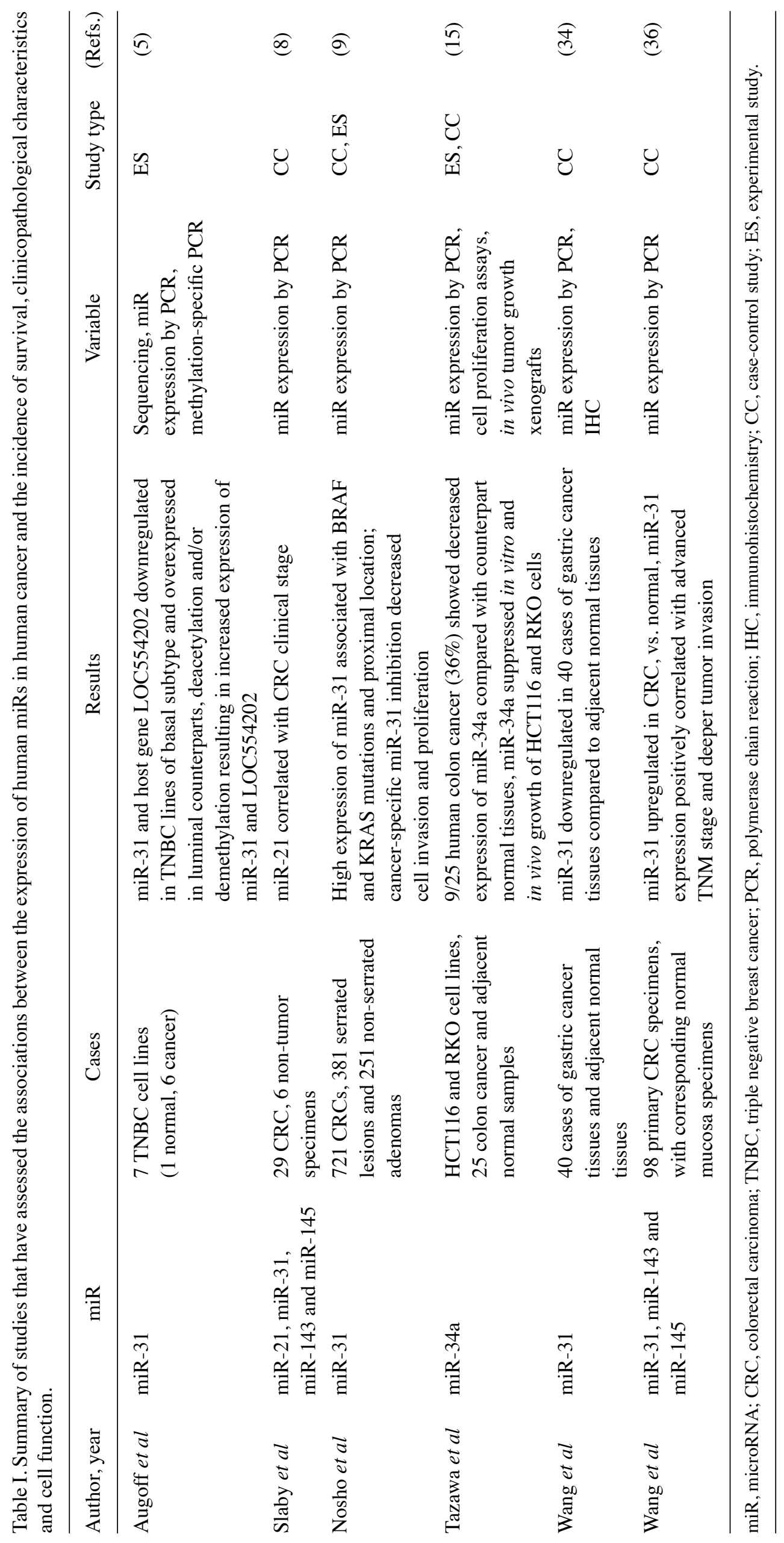


streptavidin-biotin complex amplifiers were added for $60 \mathrm{~min}$ at $37^{\circ} \mathrm{C}$, and chromogen 3,3'-diaminobenzidine tetrahydrochloride (DAB) was applied as a $0.02 \%$ solution containing $0.005 \% \mathrm{H}_{2} \mathrm{O}_{2}$ in $50 \mathrm{mM}$ ammonium acetate-citrate acid buffer (pH 6.0). The sections were lightly counterstained with Mayer's hematoxylin and mounted on an Nikon ECLIPSE 80i microscope (Nikon). The probes used for LOC554202 and miR-31 detection were as follows: 5'-Dig-CTGTGGCTCTTC TGGATCTCTAGG-Dig-3' and 5'-Dig-AGCTATGCCAGC ATCTTGCCT-Dig-3', respectively.

Microarray analysis. The TMA was scanned using a Pannoramic MIDI scanner (3D HISTECH, Budapest, Hungary) and analyzed by Quant Center software (3D HISTECH, Budapest, Hungary). An H-score evaluation was performed. The histochemistry score (H-score) was evaluated according to previous studies $(26,27)$. The process was performed as follows: The number of cells in each slice with positive staining and its staining intensity were converted into the corresponding values in order to semi-quantify the staining of the tissues. The $\mathrm{H}$-score score was obtained following scanning of the tissue with Pannoramic viewer 1.15.4 software (3D HISTECH, Budapest, Hungary). The image was enlarged, and the image of the cancer tissue was captured. The associated Quant Center Center V2.0 analysis software DensitoQuant program (3D HISTECH) was used to automatically identify and set the dark brown color on the section to as strongly positive and the brownish yellow staining as medium. Positive, light yellow staining was set as weakly positive and blue-violet staining was negative. The percentage of positive cells was identified and analyzed for each interception area. $\mathrm{H}$-score $=\Sigma(\mathrm{PI} \times \mathrm{I})=($ negative percentage $\mathrm{x} 0)+($ weak positive percentage $\mathrm{x} 1)+($ medium positive percentage $\mathrm{x} 2)+($ strong positive percentage $\mathrm{x} 3$ ), where PI represents the percentage of positive cell number, I represents the intensity of staining, and the H-score score ranges between 0 and 300 . When all cells are strongly positive, a maximum value of 300 can be reached, whereas when all cells are negative, a minimum value of 0 is reached. In this method, the number of positive cells in each section and its staining intensity are converted into corresponding values to enable the quantification of tissue staining, which is more accurate than the traditional human microscopic assessment of the degree of positivity.

Statistical analysis. Statistical analysis was performed using SPSS 20.0 (IBM Corp., Armonk, NY, USA) and GraphPad Prism 7.0 (GraphPad Software, Inc., La Jolla, CA, USA). The classification data were analyzed using Pearson's $\chi^{2}$ and/or Fisher's tests. The survival rate was calculated using the Kaplan-Meier method and the log-rank test. The multivariate COX proportional hazard regression model was used to evaluate the association of multiple variables. $\mathrm{P}<0.05$ was considered to indicate a statistically significant difference.

\section{Results}

Baseline characteristics. A total of 221 patients with CRC treated with oxaliplatin-based chemotherapy were enrolled between June 2005 and March 2010 at the First Affiliated

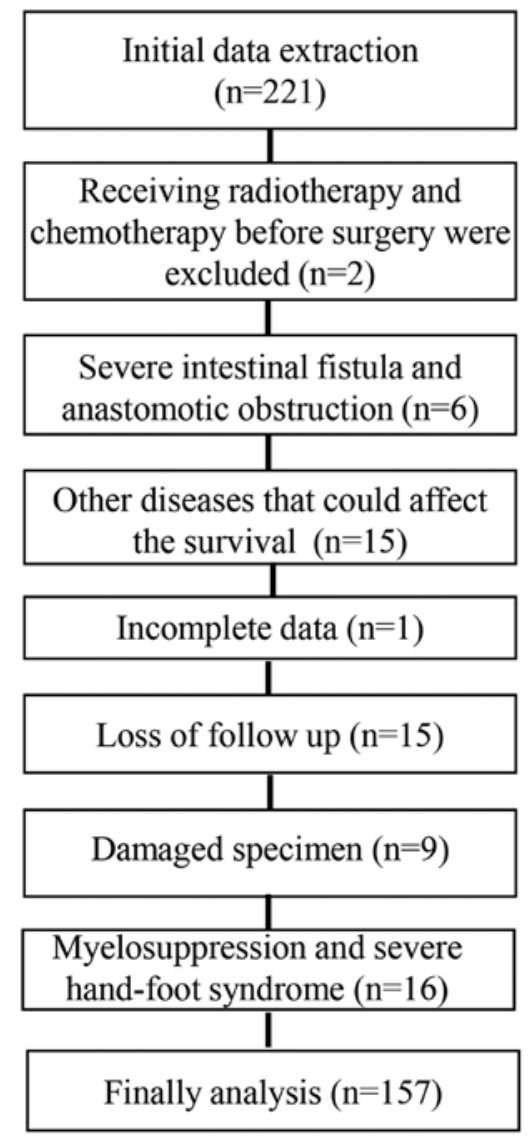

Figure 1. Flow diagram for patient enrolment.

Hospital of China Medical University. A total of 64 patients were excluded for the following reasons: Two patients were excluded due to radiotherapy and chemotherapy treatment prior to surgery, six were excluded due to severe intestinal fistula and anastomotic obstruction, 15 were excluded for having diseases that may affect the survival rate. A total of 15 patients lost contact information during follow-up, 9 had damaged specimens, and 1 was omitted due to incomplete clinical information. In addition, 16 failed to complete chemotherapy, being excluded due to myelosuppression and severe hand-foot syndrome (Fig. 1). In total, 157 patients were included for analysis, with an average age of 64 years old (17-88 years), comprising $87(55.4 .0 \%)$ men and $70(44.6 \%)$ women. The demographic data and clinical parameters, including age, sex, family history, tumor differentiation, pathological type, primary location, bowel mass, degree of invasion, tumor size, adhesions, organ metastasis and vascular infiltration, are listed in Table II. The numbers of patients presenting with Grade 1, 2 and 3 tumors were 85 (54.1\%), $60(38.2 \%)$ and $12(7.6 \%)$, respectively. The majority of the pathological types were adenocarcinoma (142 cases), whereas the remaining 15 cases were mucinous adenocarcinoma. The majority of the tumor samples were larger in the intestinal perimeter and penetrated the serosal layer; the primary location of cancer was in the colon for 75 cases $(47.8 \%)$ and the rectum for 82 cases (52.2\%). In 70 (44.6\%) cases, tumor diameter was $\geq 6 \mathrm{~cm}$, whereas 87 cases $(55.4 \%)$ exhibited a tumor diameter of $<6 \mathrm{~cm}$. The majority of the tumors indicated no adhesion, organ metastasis and/or vessel infiltration. 
Table II. Clinicopathological characteristics of patients with colorectal cancer treated with platinum-based chemotherapy.

\begin{tabular}{|c|c|c|}
\hline Characteristic & Number of cases & $\%$ \\
\hline Total & 157 & 100 \\
\hline Average age, years (range) & $64(17-88)$ & \\
\hline \multicolumn{3}{|l|}{ Age (years) } \\
\hline$\leq 64$ & 77 & 49.0 \\
\hline$>64$ & 80 & 51.0 \\
\hline \multicolumn{3}{|l|}{ Sex } \\
\hline Male & 87 & 55.4 \\
\hline Female & 70 & 44.6 \\
\hline \multicolumn{3}{|l|}{ Family history } \\
\hline Positive & 14 & 8.9 \\
\hline Negative & 143 & 91.1 \\
\hline \multicolumn{3}{|l|}{ Differentiation } \\
\hline Grade 1 & 85 & 54.1 \\
\hline Grade 2 & 60 & 38.2 \\
\hline Grade 3 & 12 & 7.6 \\
\hline \multicolumn{3}{|l|}{ Pathological pattern } \\
\hline Adenocarcinoma & 142 & 90.4 \\
\hline Mucinous adenocarcinoma & 15 & 9.6 \\
\hline \multicolumn{3}{|l|}{ Primary organ } \\
\hline Colon & 75 & 47.8 \\
\hline Rectum & 82 & 52.2 \\
\hline \multicolumn{3}{|l|}{ Intestinal tract occupation } \\
\hline$\leq 1 / 2$ & 45 & 28.7 \\
\hline$>1 / 2$ & 112 & 71.3 \\
\hline \multicolumn{3}{|l|}{ Infiltration } \\
\hline Invaded serosa & 128 & 81.5 \\
\hline Non-invaded serosa & 29 & 18.5 \\
\hline \multicolumn{3}{|l|}{ Size $(\mathrm{cm})$} \\
\hline$\leq 6$ & 87 & 55.4 \\
\hline$>6$ & 70 & 44.6 \\
\hline \multicolumn{3}{|l|}{ Adhesion } \\
\hline Negative & 149 & 94.9 \\
\hline Positive & 8 & 5.1 \\
\hline \multicolumn{3}{|l|}{ Metastasis } \\
\hline Negative & 128 & 81.5 \\
\hline Positive & 29 & 18.5 \\
\hline \multicolumn{3}{|l|}{ Vascular invasion } \\
\hline Negative & 141 & 89.8 \\
\hline Positive & 16 & 10.2 \\
\hline \multicolumn{3}{|l|}{ DFS } \\
\hline Negative & 49 & 31.2 \\
\hline Positive & 108 & 68.8 \\
\hline \multicolumn{3}{|l|}{ OS } \\
\hline Survived & 59 & 37.6 \\
\hline Deceased & 98 & 62.4 \\
\hline \multicolumn{3}{|l|}{ Follow-up, months (range) } \\
\hline DFS & $41.97(1-110)$ & \\
\hline $\mathrm{OS}$ & $53.75(6-110)$ & \\
\hline
\end{tabular}

DFS, disease-free survival; OS, overall survival.
A total of 49 cases were classified as disease-free survival (DFS) subjects accounting for $31.2 \%$ of the total sample size, whereas 108 cases $(68.8 \%)$ exhibited CRC progression. The average DFS time was 41.90 months (1-110 months); a total of $59(37.6 \%)$ patients survived, whereas $98(62.4 \%)$ patients succumbed to the disease. The mean OS time was 53.75 months (6-110 months).

Expression and correlation of LOC554202 and miR-31. LOC554202 and miR-31 were positively expressed in the nucleus and cytoplasm in cancer tissues (Fig. 2A and B), whereas their expression was relatively weak in the adjacent tissues (Fig. 2C and D). The expression score of LOC554202 in CRC was $155.24 \pm 59.94$, which was significantly higher than that noted in the adjacent tissues [64.16 $28.95(0-1$ 17)] (Fig. 2E). The expression of miR-31 in CRC cancer was $226.80 \pm 43.47$ (0-276), which was significantly higher

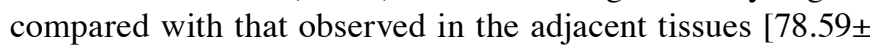
28.70 (7-166)] (Fig. 2F). Linear regression analysis indicated a significant positive correlation between the expression of LOC554202 and miR-31 in CRC ( $<<0.01$, Fig. 2G). No correlation was noted between the expression of LOC554202 and miR-31 in normal mucosal tissues (Fig. 2H). The results indicated that the expression levels of LOC554202 and miR-31 were correlated in CRC but were not correlated in adjacent normal tissues.

Analysis of LOC554202 and miR-31 in CRC by the receiver operating characteristic (ROC) curve. The H-score scores of LOC554202 and miR-31 in the CRC tissues were quantified and classified. In the present study, the H-score of LOC554202 was determined as follows: Scores of 0-70 were classified as 1 , scores of 71-140 as 2, scores of 141-210 as 3, and scores of $>211$ as 4; the miR-31 H-scores were determined as follows: 0-85 was classified as 1, 86-170 was classified as 2, 171-230 was classified as 3 , and scores $>230$ were classified as 4 .

An ROC curve was used to evaluate the optimal cut-off value for LOC554202 and miR-31. The results indicated that it was possible to distinguish the expression levels of LOC554202 by the primary position of the CRC $(\mathrm{P}=0.008)$, the pathological type $(\mathrm{P}=0.010)$, the DFS $(\mathrm{P}=0.025)$ and the OS $(\mathrm{P}=0.016)$ (Fig. 3A-D). In addition, it was possible to distinguish the expression levels of miR-31 by the pathological type $(\mathrm{P}=0.040)$, the DFS $(\mathrm{P}=0.038)$ and the OS $(\mathrm{P}=0.036)$ (Fig. 3F-H), although the primary position was not effectively distinguished $(\mathrm{P}=0.421)$. The largest area under the curve (AUC) of the ROC curve corresponded to the pathological type (Fig. 3B and F). Therefore, the ROC curve of the pathological type was selected for reference. Based on these data, a $65 \%$ cut-off (H-score of 165) was defined for the expression level of LOC554202, and an 83\% cut-off value (H-score of 230) was defined for the expression level of miR-31.

Association between the expression levels of LOC554202 and miR-31 and clinicopathological parameters of patients with $C R C$ treated with platinum-based chemotherapy. In order to investigate whether the expression levels of LOC554202 and miR-31 in CRC tissues correlated with the clinicopathological parameters of the patients with CRC, Pearson's $\chi^{2}$ test was used and logistic regression was adjusted to analyze the 
A

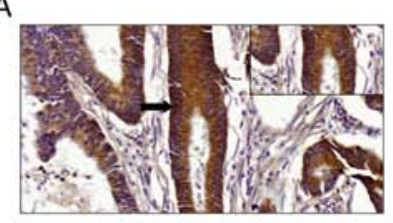

E

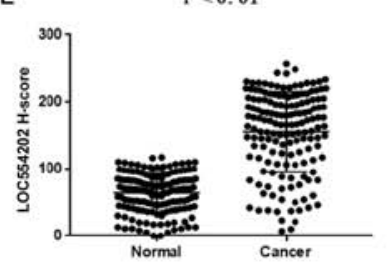

B

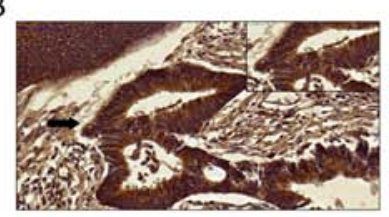

$\mathrm{F}$

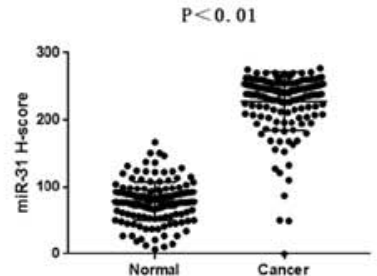

C

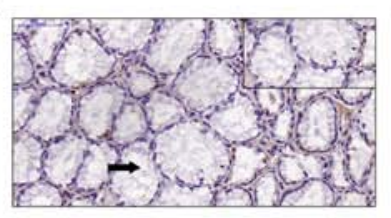

G

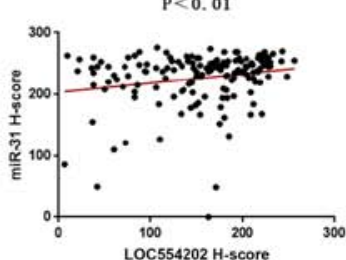

D

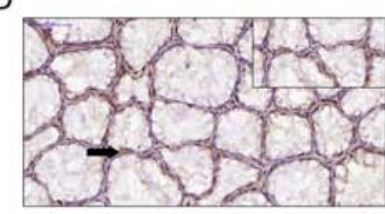

$\mathrm{H}$

$\mathrm{P}>0.05$

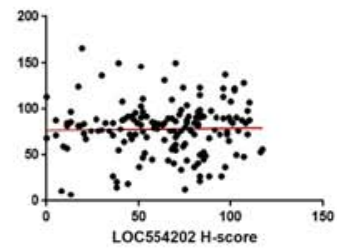

Figure 2. In situ hybridization of LOC554202 and miR-31 in (A and B) CRC tissues and (C and D) normal intestinal mucosa. The arrows indicate the representative staining parts in images (magnification, x400). (E) LOC554202 and (F) miR-31 H-scores in normal colorectal mucosa and CRC. Correlations between LOC554202 and miR-31 in (G) CRC and (H) normal colorectal mucosa were analyzed by linear regression analysis. CRC, colorectal cancer; miR, microRNA.

A

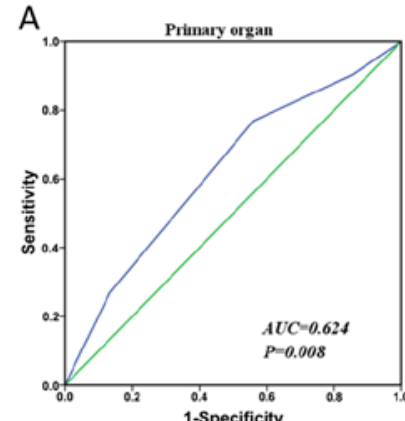

E

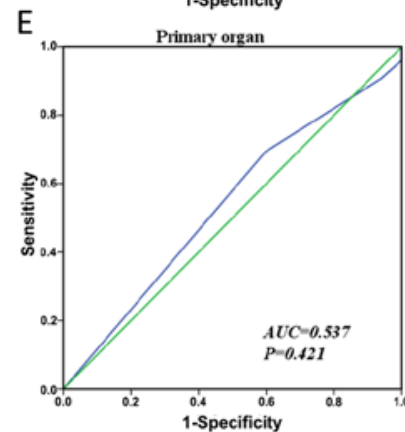

B

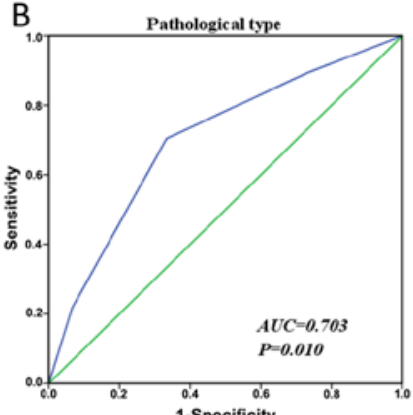

$\mathrm{F}$

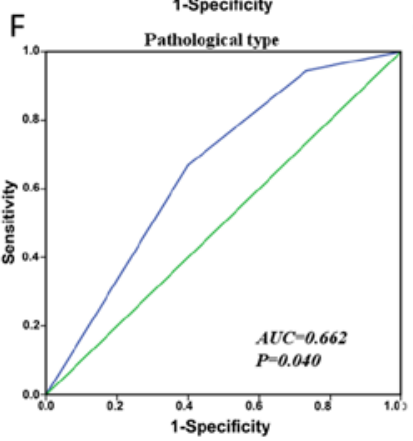

C

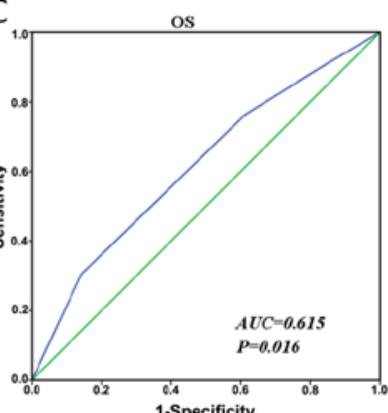

G

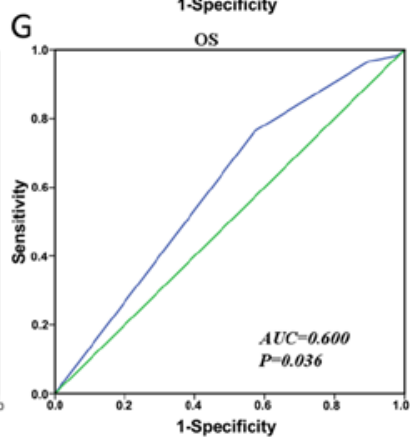

D

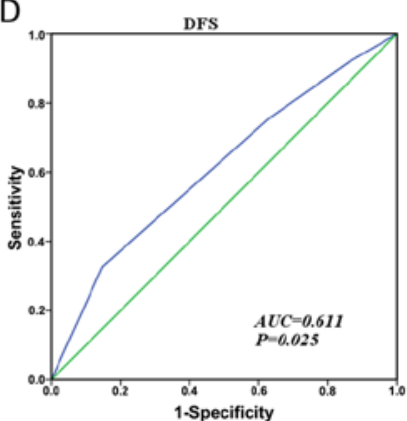

$\mathrm{H}$

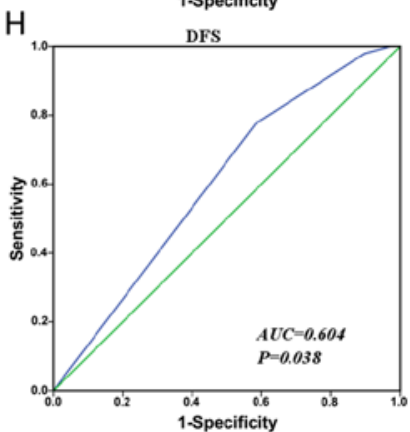

Figure 3. ROC curves were used to determine the cut-off scores for LOC554202 and miR-31 in colorectal cancer. The sensitivity and specificity for each outcome were plotted and the AUC and P-values were calculated. ROC curves for LOC554202 and (A) primary organ, (B) pathological type, (C) OS, and (D) DFS. ROC curves for miR-31 and (E) primary organ, $(\mathrm{F})$ pathological type, $(\mathrm{G})$ OS and (H) DFS. miR, microRNA; ROC, receiver operating character; AUC, area under the curve; DFS, disease-free survival; OS, overall survival.

correlation between the expression of LOC554202 and/or miR-31, the co-expression of LOC554202 and miR-31, and the clinicopathological parameters.

Following stratification of the analysis of the pathological types, it was concluded that $54.2 \%$ of the patients with adenocarcinoma exhibited a high expression of LOC554202, whereas only $13.3 \%$ of the patients with mucinous adenocarcinoma expressed LOC554202 [P=0.003, adjusted logistic regression analysis $\mathrm{P}=0.007$, adjusted $\mathrm{OR}(95 \% \mathrm{CI})=0.116(0.025-0.548)]$. The expression of miR-31 was high in $66.9 \%$ of the CRC tissues from the patients with adenocarcinoma, and patients with high expression of miR-31 accounted for $40 \%$ of patients with mucinous adenocarcinoma $(\mathrm{P}=0.039)$. Following adjustment by logistic regression analysis, the parameters were as follows: $\mathrm{P}=0.038$, adjusted $\mathrm{OR}(95 \% \mathrm{CI})=0.308(0.101-0.937)$. These data suggested that the elevated expression levels of miR-31 and LOC554202 were likely to occur in patients with adenocarcinoma (Table III).

In the primary location stratification analysis, $61 \%$ of patients with rectal cancer exhibited high expression of LOC554202, whereas only $38.7 \%$ of patients with colon cancer exhibited high expression of LOC554202 ( $\mathrm{P}=0.005)$. The adjusted logistic regression analysis demonstrated the following parameters: $\mathrm{P}=0.007$, corresponding adjusted $\mathrm{OR}$ $(95 \% \mathrm{CI})=2.502(1.290-4.850)$. Based on these results, it was deduced that higher expression levels of LOC554202 were more likely to occur in rectal cancer than in colon cancer (Table III). 


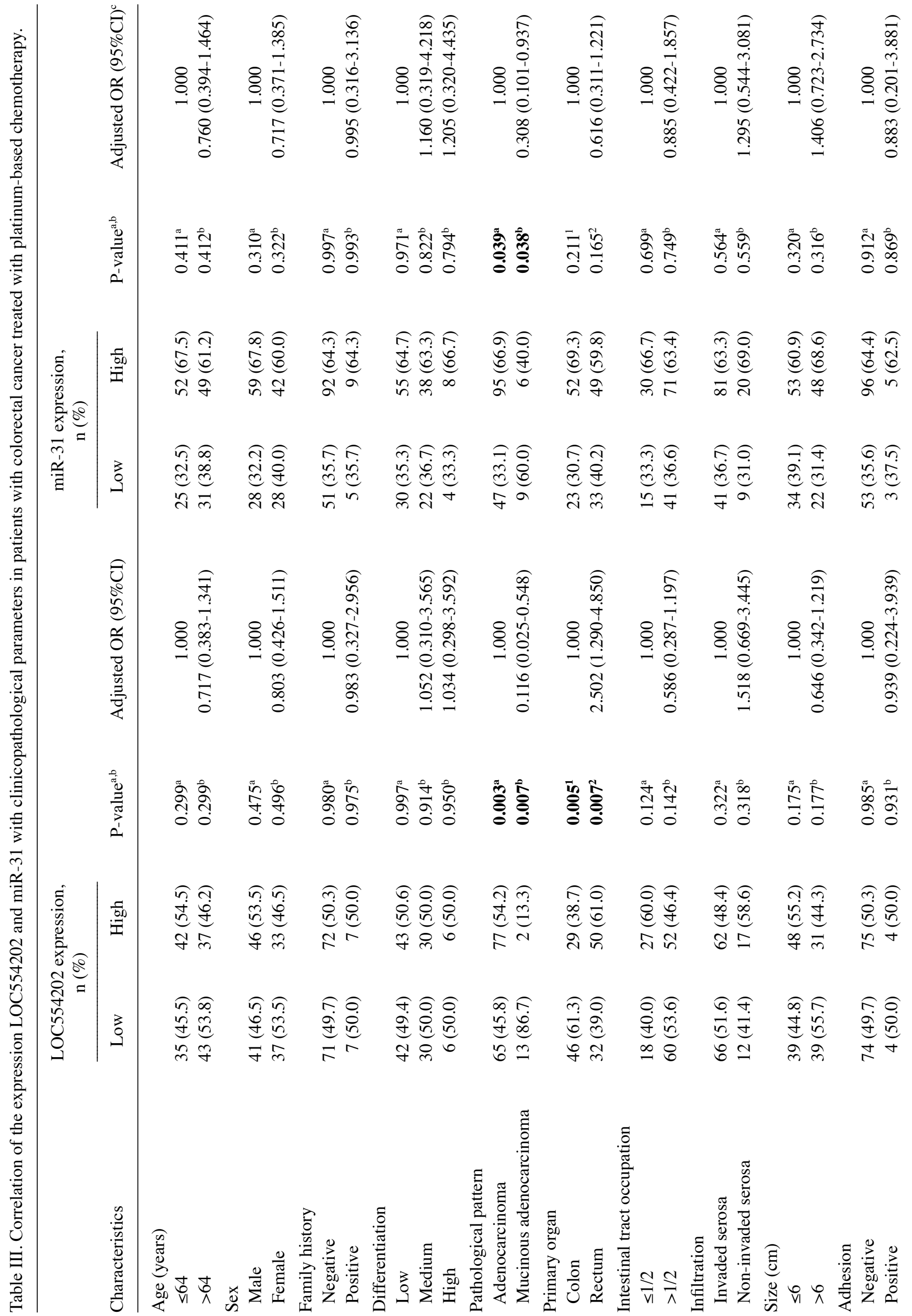




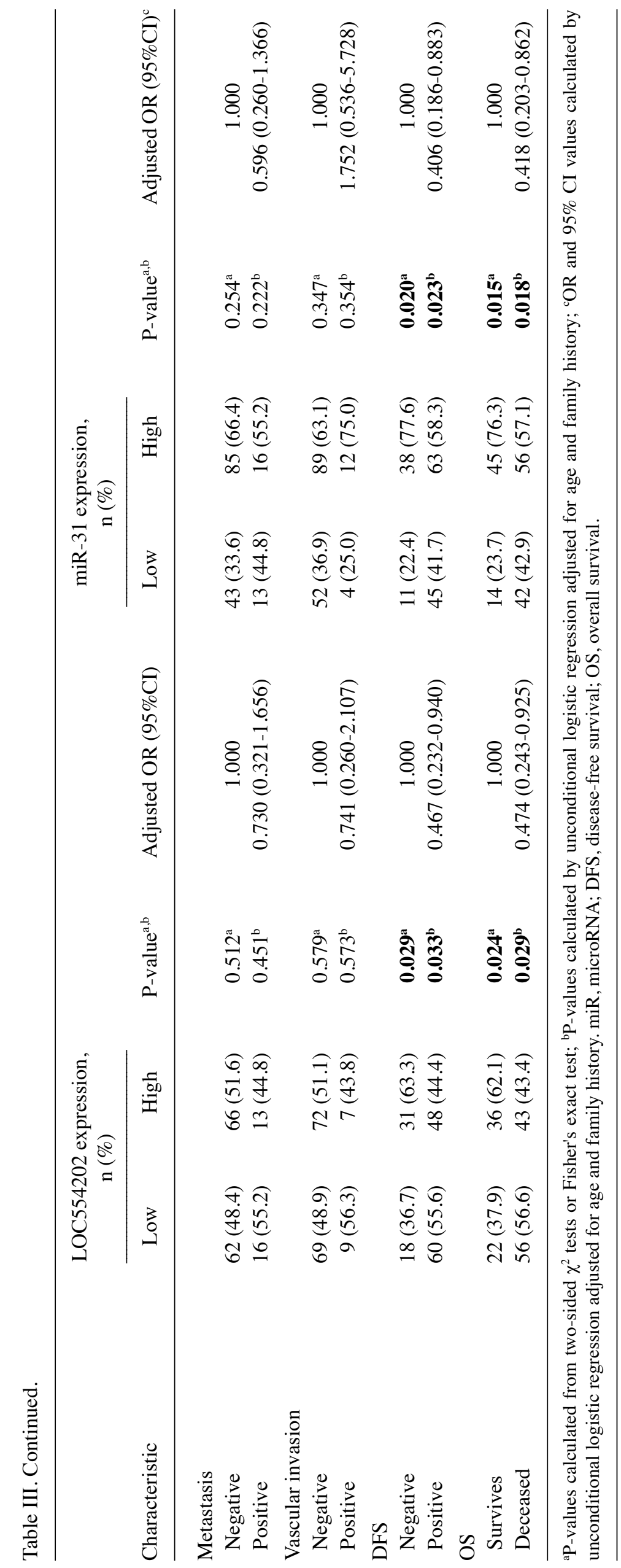


Analysis of DFS indicated that $44.4 \%$ of the patients with tumor progression exhibited high expression of LOC554202, whereas the percentage of patients without disease progression was $63.3 \%$. The data suggested that DFS exhibited a significant correlation with the expression of LOC554202 $(\mathrm{P}=0.029)$. The parameters estimated by the adjusted logistic regression analysis were as follows: $\mathrm{P}=0.033$, corresponding adjusted $\mathrm{OR}$ $(95 \% \mathrm{CI})=0.467(0.232-0.940)$. In addition, miR-31 exhibited high expression in $58.6 \%$ of patients with tumor progression and $77.6 \%$ of patients without tumor progression. The proportion with elevated expression of miR-31 was higher in the population without tumor progression $(\mathrm{P}=0.020)$. The $\mathrm{P}$-value and $\mathrm{OR}$ derived by logistic regression analysis were $\mathrm{P}=0.023$ and adjusted OR $(95 \% \mathrm{CI})=0.406(0.186-0.883)$, respectively The aforementioned results indicated that patients with low expression levels of LOC554202 and miR-31 were more prone to tumor progression (Table III).

Following assessment of the variable OS, the results indicated that $62.5 \%$ of patients exhibited high expression levels of LOC554202 in surviving patients, whereas only $43.4 \%$ of the patients who succumbed to mortality exhibited high expression of LOC554202 ( $\mathrm{P}=0.024)$. The data were analyzed by logistic regression analysis and the results were as follows: $\mathrm{P}=0.029$ and adjusted OR $(95 \% \mathrm{CI})=0.474(0.243-0.925)$. The expression of miR-31 was high in $57.1 \%$ of patients who succumbed to mortality and $76.3 \%$ of patients who survived. The elevated expression of miR-31 was significantly different between these two groups of patients $[\mathrm{P}=0.015$, adjusted by logistic regression analysis: $\mathrm{P}=0.018$, adjusted $\mathrm{OR}(95 \% \mathrm{CI})=0$ .418 (0.203-0.862). These data indicated that patients with high expression levels of miR-31 and LOC554202 were more likely to survive (Table III).

No significant differences were found between the expression of miR-31 and/or LOC554202 and age, sex, family history, tumor differentiation, tumor size, infiltration, adhesions and/or organ metastasis were noted (Table III).

The correlation between the elevated expression levels of LOC554202 and miR-31 and the clinicopathological parameters of patients treated with platinum-based chemotherapy for CRC were analyzed. The patients that exhibited high expression of miR-31 had high expression of LOC554202 in the colon and in the rectum at percentages of 44.2 and $67.3 \%$, respectively. This association was significant $(\mathrm{P}=0.019)$ and the $\mathrm{P}$-value was decreased following adjusted logistic regression analysis $[\mathrm{P}=0.015$, adjusted $\mathrm{OR}(95 \% \mathrm{CI})=2.857(1.127-6.651)]$. LOC554202 and miR-31 were expressed at high levels concomitantly in the rectum (Table IV). In the tumor progression group of subjects, $71.1 \%$ of patients with high expression of LOC554202 presented without tumor progression, whereas $46.0 \%$ of patients with high expression of LOC554202 were noted in the tumor progression group $(\mathrm{P}=0.014)$. The corresponding statistical parameters following adjustment by logistic regression analysis were as follows: $\mathrm{P}=0.008$, adjusted OR $(95 \% \mathrm{CI})=0.301(0.124-0.726)$ (Table IV). Therefore, LOC554202 and miR-31 exhibited synergistic high expression, which was correlated with the inhibition of tumor progression. Among patients who survived and those who succumbed to mortality, expression of LOC554202 was high in 71.1 and $42.5 \%$, respectively $(\mathrm{P}=0.005)$. The corresponding statistical parameters following adjustment by logistic regression analysis were as follows: $\mathrm{P}=0.004$, adjusted OR $(95 \% \mathrm{CI})=0.283(0.121-0.662)$. The co-expression of LOC554202 and miR-31 were associated with higher survival rates (Table IV).

In patients with colon cancer, $56.0 \%$ of the subjects had high expression of LOC554202 in the absence of tumor progression. However, only $30.0 \%$ of patients with tumor progression exhibited high expression of LOC554202 [P=0.029, adjusted by logistic regression $\mathrm{P}=0.034$, corresponding adjusted $\mathrm{OR}$ $(95 \%$ CI $)=0.334(0.121-0.921)]$ (Table IV). Therefore, it was hypothesized that the elevated expression of LOC554202 is associated with the inhibition of the progression of colon cancer, whereas the low expression of this gene in colon cancer is more likely to facilitate the tumor progression process.

Based on the aforementioned analysis, the expression levels of miR-31, which were associated with high and/or low expression of LOC554202 in patients with CRC exhibited a significant correlation with the parameters of CRC primary location, DFS and OS (Table V).

Association between the expression of LOC554202 and/or miR-31 and the survival rates of patients with CRC treated with platinum-based chemotherapy. The single factor log-rank test and the multivariate Cox survival risk regression model were used to analyze the correlation between LOC554202 and miR-31 and the prognosis of patients with CRC treated with oxaliplatin.

The mean DFS of patients with high expression of LOC554202 was 56.246 months, and the 95\% CI was 46.733-65.759 months. The mean DFS of patients with low expression of LOC554202 was 40.68 months and the 95\% CI was 31.765-49.492 months (log-rank: $\mathrm{P}=0.018$, Fig. 4A). The results indicated that a high expression of LOC554202 significantly prolonged the patient DFS $(95 \% \mathrm{CI})=0.647(0.441-0.9$ 49), $\mathrm{P}=0.026$ (Table VI); the expression of LOC554202 was significantly higher than that in the control group $(\mathrm{P}<0.05)$. Further analysis of the correlation between LOC554202 and OS indicated that the mean survival time (MST) of patients with high expression of LOC554202 who received oxaliplatin was 67.12 months. The 95\% CI was 58.72-75.53 months. Patients with a low expression of LOC554202 exhibited an MST of 56.19 months (95\% CI 48.37-64.01 months). There was a statistically significant difference according to the log-rank test results $(\mathrm{P}=0.024$, Fig. $4 \mathrm{~B})$. Cox analysis further indicated that a high expression of LOC554202 was a protective factor for OS prolongation, corresponding to HR $(95 \%$ CI $)=0.64$ (0.43-0.96), P=0.031 (Table VI).

In addition, significant correlations between the differential expression of LOC554202 in patients with colon cancer $(n=75)$ and the DFS and OS were noted (Fig. 4C and D). The mean DFS of the patients with high expression of LOC554202 was 64.19 months and the 95\% CI was 49.34-78.67 months. The mean DFS of patients with low expression of LOC554202 was 39.74 months and the $95 \%$ CI was $28.89-50.59$ months. The data indicated that the high expression of LOC554202 significantly prolonged the DFS in patients with colon cancer. Furthermore, the results indicated that the MST of patients with high expression of LOC554202 was 74.78 months and the $95 \%$ CI was $62.988-86.761$ months, whereas the MST of patients with a low expression of LOC554202 was 58.3 months 
Table IV. Correlation between the expression of LOC554202 and miR-31 status in patients with colorectal cancer treated with platinum-based chemotherapy

\begin{tabular}{|c|c|c|c|c|}
\hline \multirow[b]{2}{*}{ Characteristic } & \multicolumn{2}{|c|}{ LOC554202 expression } & \multirow[b]{2}{*}{ P-value ${ }^{a, b}$} & \multirow[b]{2}{*}{ Adjusted OR (95\% CI) } \\
\hline & Low & High & & \\
\hline \multicolumn{5}{|l|}{ All patients } \\
\hline \multicolumn{5}{|l|}{ miR-31 } \\
\hline Low expression & $33(58.9)$ & $23(41.1)$ & $0.084^{\mathrm{a}}$ & 1 (reference) \\
\hline High expression & 45 (44.6) & $56(55.4)$ & $0.097^{\mathrm{b}}$ & $1.754(0.903-3.408)$ \\
\hline \multicolumn{5}{|c|}{ miR-31 low expression } \\
\hline \multicolumn{5}{|l|}{ Primary organ } \\
\hline Colon & 17 (73.9) & $6(26.1)$ & $0.057^{\mathrm{a}}$ & 1 (reference) \\
\hline Rectum & $16(48.5)$ & $17(51.5)$ & $0.216^{\mathrm{b}}$ & $2.141(0.642-7.143)$ \\
\hline \multicolumn{5}{|l|}{ DFS } \\
\hline Negative & $7(63.6)$ & $4(36.4)$ & $0.723^{\mathrm{a}}$ & 1 (reference) \\
\hline Positive & $26(57.8)$ & $19(42.2)$ & $0.683^{b}$ & $1.345(0.325-5.572)$ \\
\hline \multicolumn{5}{|l|}{ OS } \\
\hline Negative & $9(64.3)$ & $5(35.7)$ & $0.638^{\mathrm{a}}$ & 1 (reference) \\
\hline Positive & $24(57.1)$ & $18(42.9)$ & $0.511^{\mathrm{b}}$ & $1.551(0.419-5.743)$ \\
\hline \multicolumn{5}{|c|}{ miR-31 high expression } \\
\hline \multicolumn{5}{|l|}{ Primary organ } \\
\hline Colon & $29(55.8)$ & $23(44.2)$ & $0.019^{\mathrm{a}}$ & 1 (reference) \\
\hline Rectum & $16(32.7)$ & $33(67.3)$ & $0.015^{b}$ & $2.857(1.127-6.651)$ \\
\hline \multicolumn{5}{|l|}{ DFS } \\
\hline Negative & $11(28.9)$ & $27(71.1)$ & $0.014^{\mathrm{a}}$ & 1 (reference) \\
\hline Positive & $34(54.0)$ & $29(46.0)$ & $\mathbf{0 . 0 0 8}^{\mathrm{b}}$ & $0.301(0.124-0.726)$ \\
\hline \multicolumn{5}{|l|}{ OS } \\
\hline Negative & 13 (28.9) & $32(71.1)$ & $0.005^{\mathrm{a}}$ & 1 (reference) \\
\hline Positive & $32(57.1)$ & $24(42.9)$ & $0.004^{b}$ & $0.283(0.121-0.662)$ \\
\hline \multicolumn{5}{|c|}{ Primary organ: Colon } \\
\hline \multicolumn{5}{|l|}{ miR-31 } \\
\hline Low expression & 17 (73.9) & $6(26.1)$ & $0.137^{\mathrm{a}}$ & 1 (reference) \\
\hline High expression & $29(55.8)$ & $23(44.2)$ & $0.143^{b}$ & $2.257(0.759-6.710)$ \\
\hline \multicolumn{5}{|l|}{ DFS } \\
\hline Negative & $11(44.0)$ & $14(56.0)$ & $0.029^{a}$ & 1 (reference) \\
\hline Positive & $35(70.0)$ & $15(30.0)$ & $0.034^{b}$ & $0.334(0.121-0.921)$ \\
\hline \multicolumn{5}{|l|}{ OS } \\
\hline Negative & $15(48.4)$ & $16(51.6)$ & $0.053^{\mathrm{a}}$ & 1 (reference) \\
\hline Positive & $31(70.5)$ & $13(29.5)$ & $0.060^{\mathrm{b}}$ & $0.394(0.150-1.039)$ \\
\hline \multicolumn{5}{|c|}{ Primary organ: Rectum } \\
\hline \multicolumn{5}{|l|}{ miR-31 } \\
\hline Low expression & $16(48.5)$ & $17(51.5)$ & $0.150^{\mathrm{a}}$ & 1 (reference) \\
\hline High expression & $16(32.7)$ & $33(67.3)$ & $0.256^{\mathrm{b}}$ & $1.708(0.678-4.301)$ \\
\hline \multicolumn{5}{|l|}{ DFS } \\
\hline Negative & $7(29.2)$ & $17(70.8)$ & $0.239^{\mathrm{a}}$ & 1 (reference) \\
\hline Positive & $25(43.1)$ & 33 (56.9) & $0.177^{\mathrm{b}}$ & $0.492(0.175-1.378)$ \\
\hline \multicolumn{5}{|l|}{ OS } \\
\hline Negative & $7(25.0)$ & $21(75.0)$ & $0.061^{\mathrm{a}}$ & 1 (reference) \\
\hline Positive & $25(46.3)$ & $29(53.7)$ & $0.040^{b}$ & $0.343(0.124-0.951)$ \\
\hline
\end{tabular}

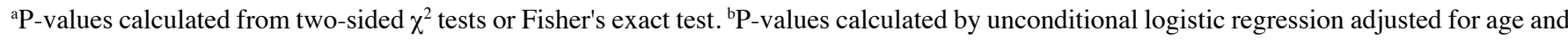
pathological pattern. ${ }^{\circ} \mathrm{OR}$ and $95 \% \mathrm{CI}$ values were calculated by unconditional logistic regression adjusted for age and family history. miR, microRNA; DFS, disease-free survival; OS, overall survival. 
Table V.miR-31 correlation with DFS and OS in relation to high and/or low expression of LOC554202 in patients with colorectal cancer.

miR-31 expression

Characteristic

Low High

P-value ${ }^{a, b}$

Adjusted OR $(95 \% \mathrm{CI})^{\mathrm{c}}$

Loc554202 low expression

Primary organ

\section{Colon}

Rectum

DFS

Negative

Positive

OS

Negative

Positive

Loc554202 high expression

Primary organ

\section{Colon}

Rectum

DFS

Negative

Positive

OS

Negative

Positive

Primary organ: Colon

Loc554202

Low expression

High expression

17

6 (20.7)

17 (33.3)

4 (12.9)

19

17 (37.0)

$16(50.0)$

$29(63.0)$

$16(50.0)$

7 (38.9)

26 (43.3)

9 (40.9)

24 (42.9)

$11(61.1)$

34 (56.7)

13 (59.1)

$32(57.1)$

$23(79.3)$

33 (64.7)

$0.209^{\mathrm{a}}$

$0.284^{\mathrm{b}}$

$0.875^{\mathrm{a}}$

$0.921^{\mathrm{b}}$

27 (87.1)

29

$0.011^{\mathrm{a}}$

$0.007^{\mathrm{b}}$

32

5

18

24

$0.004^{\mathrm{a}}$

$\mathbf{0 . 0 0 3}^{\mathrm{b}}$

$0.137^{\mathrm{a}}$

$0.143^{\mathrm{b}}$

$0.013^{\mathrm{a}}$

$0.023^{b}$

$0.005^{\mathrm{a}}$

$0.008^{b}$
22

30

27

25

19

Primary organ: Rectum

Loc554202

Low expression

High expression

16

17

DFS

Negative

Positive

OS

Negative

Positive

8

25

10

23
16

$0.150^{\mathrm{a}}$

$0.256^{\mathrm{b}}$

$0.412^{\mathrm{a}}$

$0.309^{b}$

$0.547^{\mathrm{a}}$

$0.404^{\mathrm{b}}$
1 (reference)

0.409 (0.151-1.104)

1 (reference)

0.910 (0.301-2.749)

1 (reference)

0.949 (0.339-2.655)

1 (reference)

0.548 (0.182-1.645)

1 (reference)

0.185 (0.055-0.626)

1 (reference)

0.176 (0.056-0.553)

1 (reference)

2.254 (0.759-6.698)

1 (reference)

0.208 (0.054-0.804)

1 (reference)

0.185 (0.054-0.638)

1 (reference)

1.708 (0.678-4.301)

1 (reference)

0.591 (0.215-1.629)

1 (reference)

0.664 (0.254-1.738)

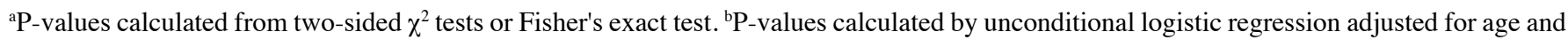
pathological pattern. ${ }^{\circ} \mathrm{OR}$ and $95 \% \mathrm{CI}$ values were calculated by unconditional logistic regression adjusted for age and family history. miR, microRNA; DFS, disease-free survival; OS, overall survival.

with a $95 \%$ CI range of $48.48-67.58$ months $(\mathrm{P}=0.029$, Fig. 4D).
The patients were further stratified and analyzed according to expression levels of miR-31. A significant correlation 


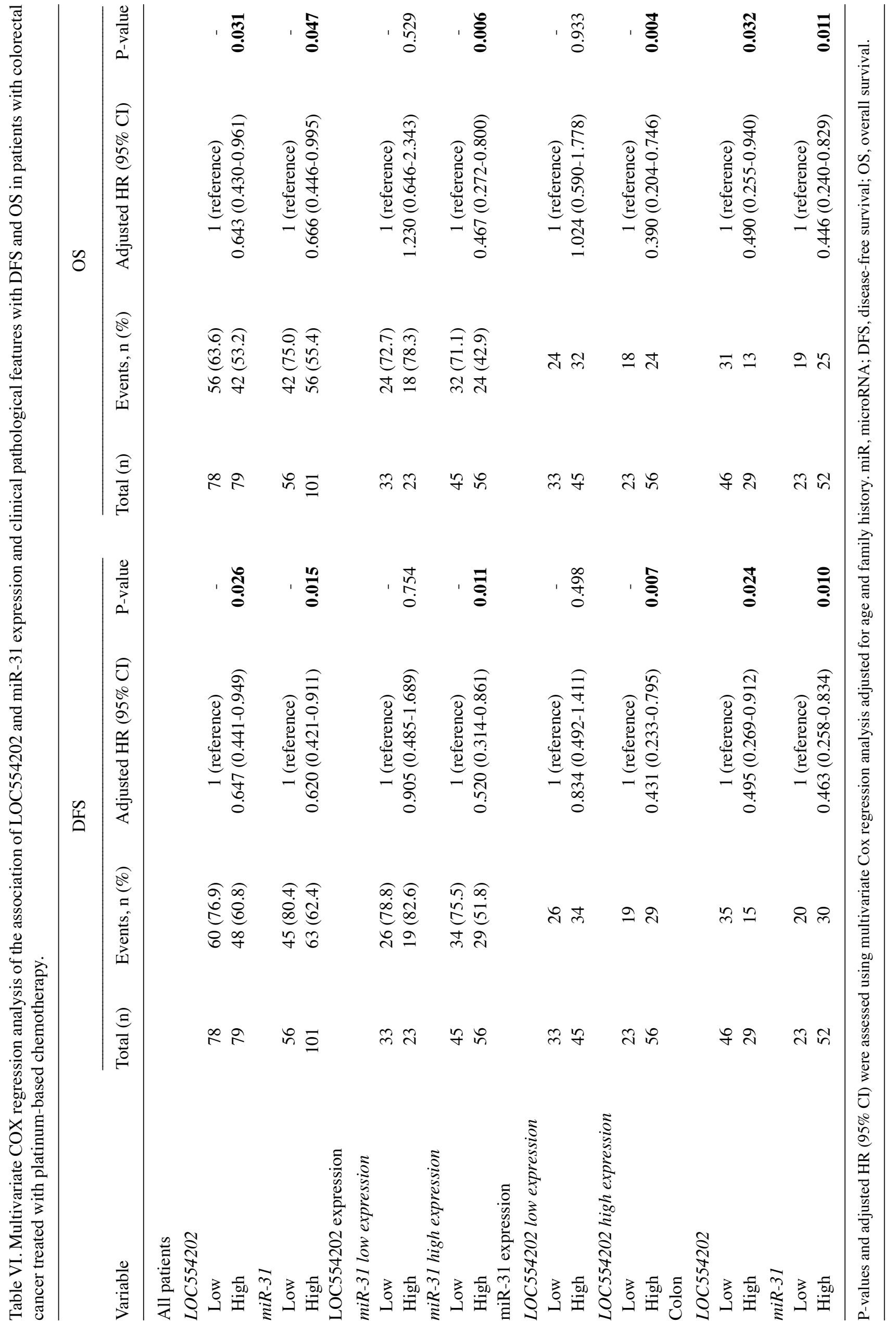



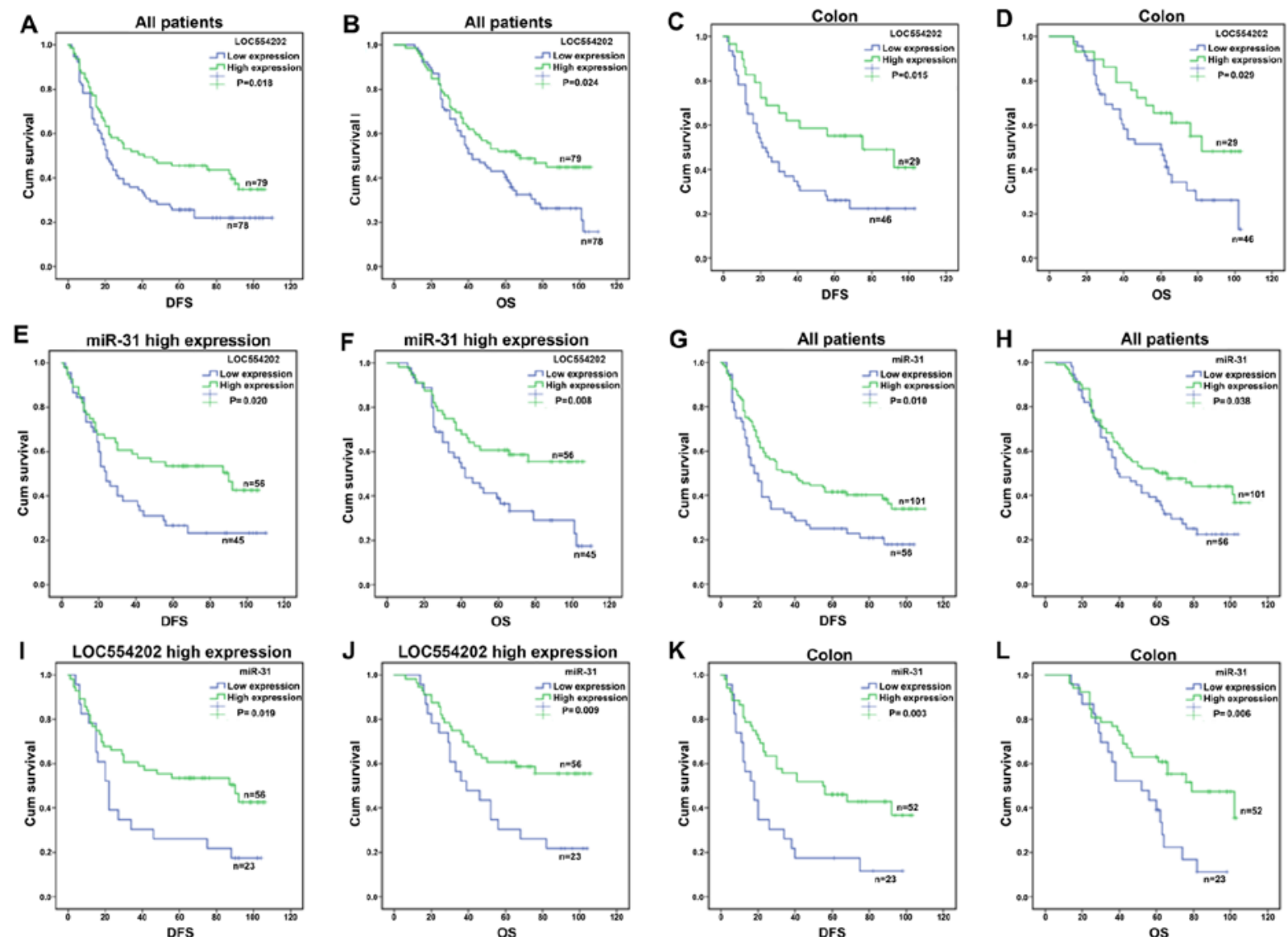

Figure 4. Kaplan-Meier survival analysis of the expression of LOC554202 and miR-31 in patients with colon cancer. Kaplan-Meier for LOC554202: All patients (A) DFS and (B) OS; Colon: (C) DFS and (D) OS; miR-31 high expression: (E) DFS and (F) OS. Kaplan-Meier for miR-31: All patients: (G) DFS and (H) OS; LOC554202 high expression: (I) DFS and (J) OS; Colon: (K) DFS and (L) OS. miR, microRNA; DFS, disease-free survival; OS, overall survival.
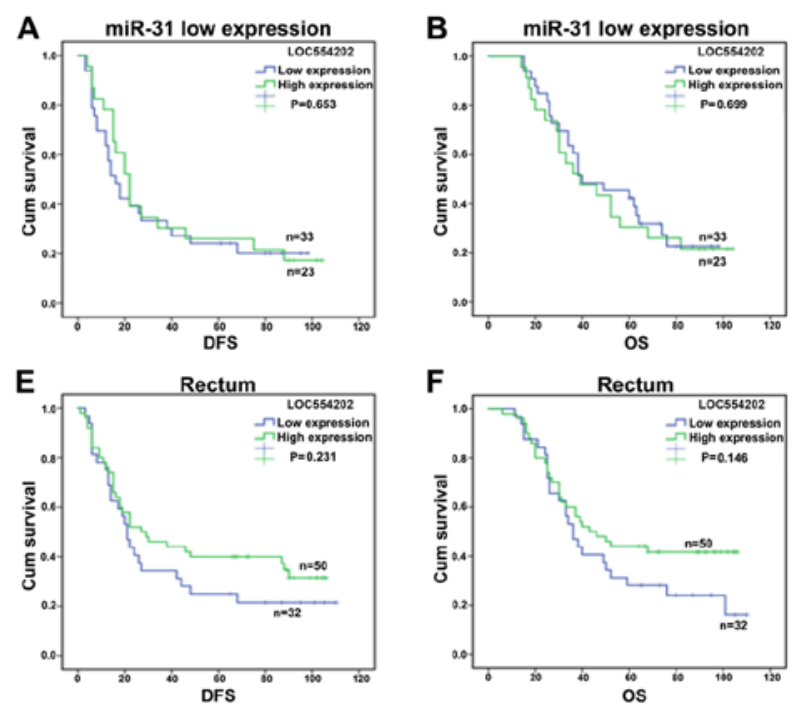
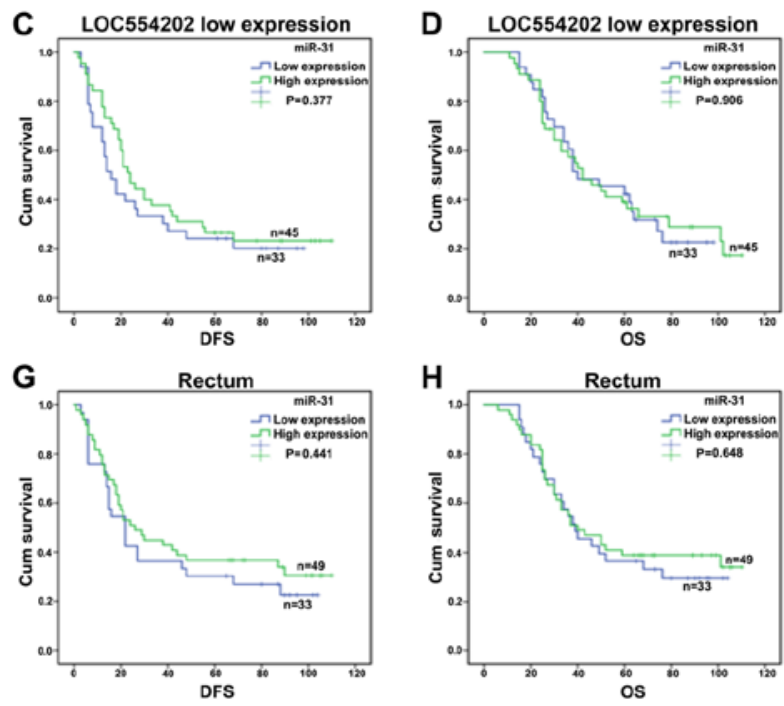

Figure 5. Kaplan-Meier survival analysis of the expression of LOC554202 and miR-31 in patients with rectal cancer. The miR-31 and LOC554202 increasing the DFS and OS times was present in patients with colon cancer but not in patients with rectal cancer. miR-31 low expression: (A) DFS and (B) OS; LOC554202 low expression: (C) DFS and (D) OS; Rectum (E) DFS and (F) OS; Rectum: (G) DFS and (H) OS. miR, microRNA; DFS, disease-free survival; OS, overall survival.

between the differential expression of LOC554202 and the DFS and OS in patients with high expression of miR-31 was noted ( $n=101)$ (Fig. 4E and F). The mean DFS of patients with high co-expression of miR-31 and LOC554202 $(n=56)$ was 63.61 months (95\% CI was 52.18-75.05 months), whereas the mean DFS of patients with low expression of LOC554202 and high expression of miR-31 $(n=45)$ was 43.70 months with a 95\% CI of 31.839-55.094 months ( $\mathrm{P}=0.020$, Fig. 4E). Corrected multivariate Cox analysis further suggested that a high expression of LOC554202 was a protective factor for 
DFS prolongation in patients with high expression of miR-31 [corresponding HR $(95 \% \mathrm{CI})=0.520(0.314-0.861)](\mathrm{P}=0.011)$. The analysis of OS demonstrated that the MST in patients with high expression of miR-31 and LOC554202 was 73.74 months, and the $95 \%$ CI was $63.70-83.78$ months, whereas that of the patients with low expression of LOC554202 and high expression of miR-31was 56.69 months with a 95\% CI range of 46.04-67.34 months. These parameters were statistically different according to the log-rank test $(\mathrm{P}=0.008$, Fig. 4F).

The analysis of the association between the miRNA differential expression and prognosis indicated that patients with high expression of miR-31 exhibited an average DFS of 55.582 months, with a $95 \%$ CI range of 46.93-64.24 months; the patients with low expression of miR-31 had an average DFS of 36.63 months and the $95 \% \mathrm{CI}$ was 27.02-46.24 months (log-rank: $P=0.010$, Fig. 4G). Further analysis of the correlation between miR-31 and OS demonstrated that the MST in patients with high expression of miR-31 was 67.38 months with a $95 \%$ CI range of 59.63-75.13 months, whereas the corresponding MST of the patients with low expression of miR-31 was 53.63 months and the $95 \% \mathrm{CI}$ was 45.18-62.08 months $(\mathrm{P}=0.038$, Fig. $4 \mathrm{H})$. In addition, the corrected multivariate Cox analysis indicated that a high expression of miR-31 was a protective factor for extended OS $[$ HR $(95 \%$ CI $)=0.666(0.446-0.995)](\mathrm{P}=0.047$, Table VI $)$. The same as previous studies, the mean DFS of patients with high co-expression of miR-31 and LOC554202 $(n=56)$ was 63.61 months (95\% CI was 52.18-75.05 months), whereas the mean DFS of patients with low expression of miR-31 and high expression of LOC554202 $(n=23)$ was 38.565 months with a 95\% CI of 23.838-53.293 months ( $\mathrm{P}=0.019$; Fig. 4I). Corrected multivariate Cox analysis further suggested that a high expression of miR-31 was a protective factor for DFS prolongation in patients with high expression of LOC554202 [corresponding HR $(95 \% \mathrm{CI})=0.431(0.233-0.795)](\mathrm{P}=0.007)$. The analysis of OS indicated that the MST in patients with high expression of miR-31 and LOC554202 was 73.74 months, and the 95\% CI was $63.70-83.78$ months, whereas that of the patients with low expression of miR-31 and high expression of LOC554202 was 51.391 months with a 95\% CI range of 38.208-64.574 months. These parameters were statistically different according to the log-rank test ( $\mathrm{P}=0.009$; Fig. $4 \mathrm{~J})$. Corrected multivariate Cox analysis further suggested that a high expression of miR-31 was a protective factor for MST in patients with high expression of LOC554202 [corresponding HR $(95 \% \mathrm{CI})=0.390$ (0.204-0.746)] $(\mathrm{P}=0.004)$.

The expression of miR-31 was further analyzed with regard to the primary location of the tumor. In patients with CRC, the mean DFS of the patients with a high expression of miR-31 was 57.62 months and the $95 \%$ CI was 46.46-68.77 months. The mean DFS of patients with a low expression of miR-31 was 29.49 months and the $95 \%$ CI was 17.24-41.75 months (log-rank: $\mathrm{P}=0.003$, Fig. $4 \mathrm{~K}$ ). The data indicated that miR-31 and LOC554202 not only significantly improved the DFS of patients with platinum-based chemotherapy, but also improved the OS. The association between the increase in DFS and OS and the disease incidence was present in patients with colon cancer but not in patients with rectal cancer (Fig. 5). In addition, the correlations between the remaining clinicopathological parameters and DFS and
OS were analyzed by multiple factors Cox analysis. The data demonstrated that family history $(\mathrm{P}=0.037)$ and tumor organ metastasis $(\mathrm{P}=0.033)$ were risk factors for the prognosis of patients (Table VII).

\section{Discussion}

To the best of our knowledge, the present study is the first to report that the elevated expression of miR-31 and LOC554202 are optimal predictors for the prognosis of patients with oxaliplatin-treated CRC. These findings may provide novel insights into CRC treatment.

It has been reported that at least $25 \%$ of miRNA sequences are located in the host gene, a number of which are highly conserved (28). Baskerville and Bartel reported that the majority of intron miRNAs and their host genes possess a related expression profile, where their expression levels are consistent with each other, and both are controlled by the promoter of the host gene, suggesting that they are related at a functional and/or translational level (18). However, the expression levels of certain miRNA-coding genes are inconsistent with the expression levels of their corresponding host genes, and/or the opposite pattern is observed (29). In the present study, the expression of LOC554202 was shown to be present in CRC tissues $(\mathrm{H}$-score $=155.24)$, compared with normal intestinal mucosal tissues, and the expression of miR-31 was high in $\mathrm{CRC}(\mathrm{H}$-score $=226.80)$. In addition, the expression levels of LOC554202 and miR-31 were correlated in CRC tissues in a concomitant pattern, which indicated increased and/or decreased co-expression of the two sequences. These results suggested that miR-31 may exert a regulatory role and/or a positive feedback towards the host gene LOC554202. The association between intron miRNAs and host genes remains to be fully elucidated, and different expression patterns exist between the two. It has been reported that $\sim 1 / 3$ of intron miRNAs have independent promoters and certain miRNAs have different processing pathways following transcription (30), and that these factors can lead to inconsistent expression levels of miRNAs compared with their host genes. LOC554202 and miR-31 share a common promoter (31), although additional possible mechanisms may affect the coherence of their expression.

In the present study, LOC554202 was expressed at high levels in CRC tissues compared with normal intestinal mucosal tissues, in contrast to a previous study by Ding et al (32). The levels of miR-19a, miR-21, miR-29a, miR-92, miR-148a and miR-200b were increased in CRC tissues according to miRNA expression profiles, whereas the expression of miR-30c, miR-133a and miR-145 were decreased. By comparison, it was found that the miRNA expression profiles from cell lines and cancer tissues were different. Therefore, the miRNA expression profile obtained from cell lines may not be suitable for deducing the corresponding expression profile of clinical samples. This may account for the contradictory findings reported by Augoff et al, where it was shown that both miR-31 and LOC554202 were downregulated in triple negative breast cancer cell lines (5), whereas the upregulation of these two markers was observed in the present study. It is important to note that Augoff et al investigated breast and cancer, not CRC, cell lines, thus the findings may be attributed to the different 


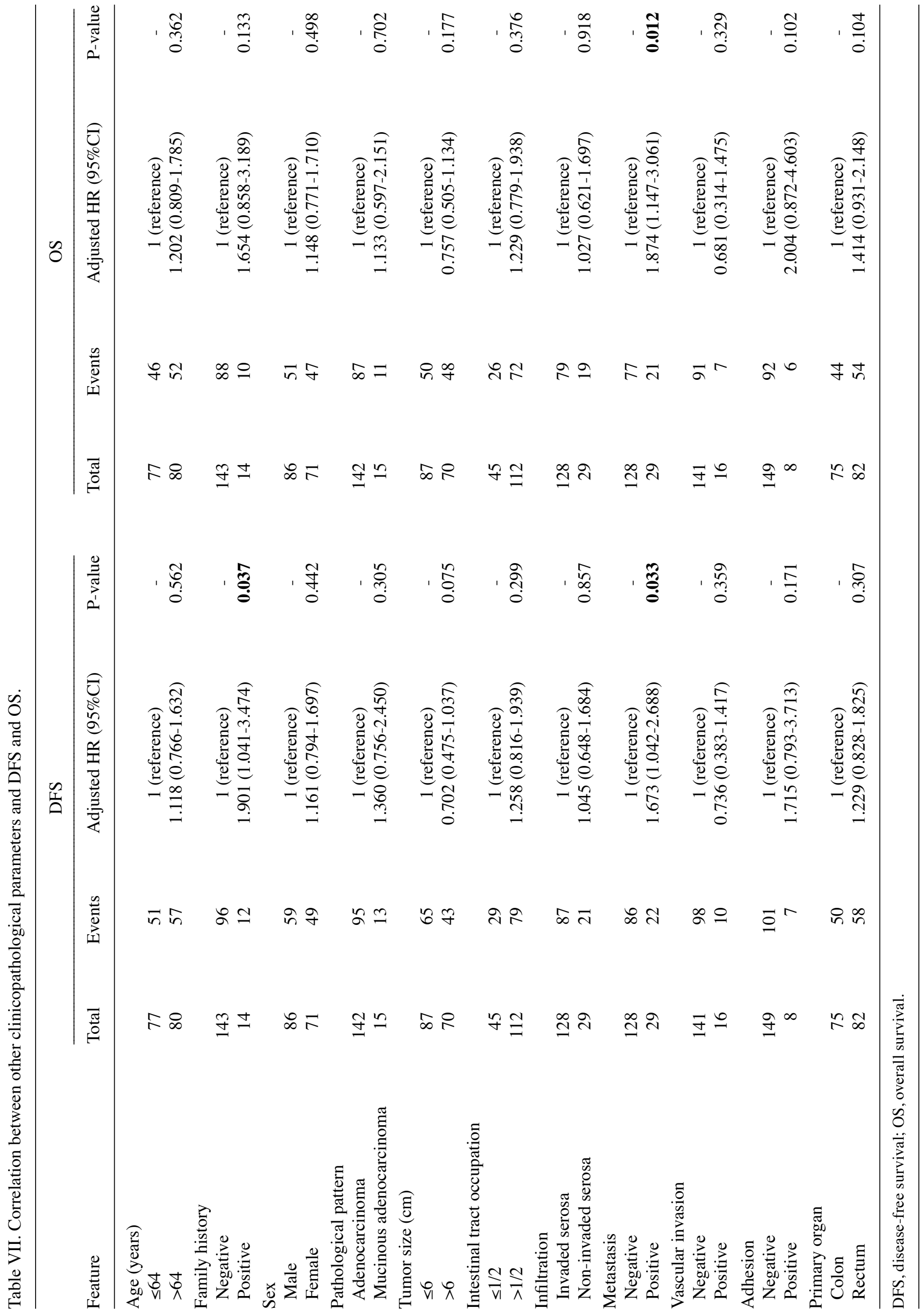


tissue origin of the tumor to that in the present study. In the low invasive breast cancer, LOC554202 and miR-31 were expressed at low levels (5). Therefore, the roles of LOC554202 in the development of the tumor are complex, depending on the different tissues of the tumor, and the different environments and conditions, all of which may have a regulatory effect on cell behavior. Bandre et al used polymerase chain reaction analysis to detect 156 miRNAs from $15 \mathrm{CRC}$ cell lines. The expression levels were compared with the corresponding expression levels in the CCD-18Co human normal colonic cell line. The authors reported that the expression levels of miR-31 were significantly different (17). In addition, the expression levels of miR-31 were associated with the clinical stage of CRC, which was significantly higher in stage IV CRC than stage II CRC. The probe hybridization technique used in the present study may be responsible for the conflicting results compared with the experimental methods applied by Yang et al (21) and Ding et al (32). However, the study by Ding et al confirmed that the expression level of LOC554202 was associated with the occurrence and development of colon cancer and its high expression was a predictor of colon cancer.

In the present study, the high expression of LOC554202 and miR-31ncRNAs prolonged the survival rate of patients with colon cancer who received chemotherapy following surgery, although no correlation in patients with rectal cancer was noted. Previous studies have shown that the role of LOC554202 in the development of tumors is complex. Shi et al demonstrated that LOC554202 was expressed at high levels in MDA-MB-231 and MDA-MB-435S breast cancer cell lines, and LOC554202 was associated with tumor staging (19). Following silencing of the LOC554202 gene, cell proliferation was decreased, apoptosis was increased, and migratory ability was decreased (19). The results of the study by Yang et al support the hypothesis that the expression of LOC554202 correlates with prognosis (21). In addition, Ding et al indicated that the expression of LOC554202 was low in CRC, and inhibited cell proliferation and induced apoptosis by activating the caspase signaling pathway (32). The results of the present study suggested that LOC554202 can be used as an independent biomarker for the prediction of the postoperative prognosis of CRC.

The high expression of miR-31 in breast cancer inhibits the activity and aggressiveness of breast cancer cells and improves the OS rate of patients (33). Studies performed in patients with gastric cancer have shown that miR-31 was expressed at low levels in cancer tissues and can inhibit cell invasion and migration (34); studies in hepatocellular carcinoma have further shown that the overexpression of miR-31 can induce the inhibition of cell proliferation and migration (35). In CRC, miR-31 is expressed at high levels in cancer tissues and cells, and its expression levels may be associated with the pathogenesis, invasion, staging, and migration of $\operatorname{CRC}(8,9,23,36)$. The results of the present study demonstrated that patients with high expression levels of LOC554202 and miR-31, who were treated with platinum-based chemotherapy postoperatively, exhibited longer DFS and OS times and reduced tumor progression, compared with patients without treatment. These findings suggested that platinum-based chemotherapeutic drugs can regulate the two lncRNA-related genes and/or signaling pathways, which may result in enhanced growth inhibition and the inhibition of CRC cell invasion.
The effects of miR-31 on the efficacy of platinum compounds have been discussed extensively. It has been shown that the expression levels of miR-31 are negatively correlated with E2F transcription factor 2 (E2F2) and Enhancer of zeste homolog 2 (EZH2) in malignant tumors including gastric, ovarian and bladder cancer, and CRC (37-41). E2F2 and EZH2 can enhance drug resistance by inhibiting platinum-drug-mediated apoptosis, whereas low expression levels of E2F2 and EZH2 enhance platinum chemosensitivity $(39,42-45)$. Li et al reported that miR-31 in gallbladder cancer sensitized tumor cells to platinum-based chemotherapy via control of the Src proto-oncogene (40). The results of the present study suggested that miR-31 was expressed at a high level in CRC and was associated with longer DFS and OS times following platinum-based chemotherapy. The data suggested that this effect may be associated with miR-31 and/or other associated factors that enhance drug sensitivity. A high expression of miR-31 in CRC may improve the cell sensitivity to platinum-based agents and enhance platinum-induced apoptosis via E2F2, EZH2 and/or associated signaling transcription factors, which may facilitate the efficacy of chemotherapeutic agents in order to increase the survival rate of the patients following chemotherapy.

The present study is in alignment with previous studies that have reported LOC554202 as a putative biomarker for CRC (21,32). Although LOC554202 was shown to be downregulated in colon tumors, its expression pattern was associated with the OS and DFS times of 178 patients with CRC, which was in agreement with the other results of the present study. In addition, miR-31 has been demonstrated to exert an oncogenic role in colon cancer, which may partly explain the elevated expression of LOC554202 in colon tumors noted in the present study (46). It is important to note that the present study is one of the few studies to have investigated the concomitant expression of miR-31 and LOC554202 in patients with CRC treated with oxaliplatin and their putative associations with DFS and OS times.

Although colonic and rectal mucosal cells exert various identical and/or similar cellular functions and signaling pathways, differences have been reported. For example, Ayiomamitis et al demonstrated that high expression levels of mutL homolog 1 (MLH1) in colon cancer tissues and adjacent normal tissues were higher than those in patients with rectal cancer and adjacent tissues (41). The silencing of MLH1 in lung cancer cells leads to increased expression of miR-31, which may be responsible for the different expression levels of miR-31 between rectal and colon cancer (47). Concomitantly, the high expression levels of miR-31 and LOC554202 in rectal cancer may be due to the feedback regulation of miR-31 toward the host gene LOC554202. However, as the length of the tumor was not counted from the distance of the anus, the hypothesis that high expression levels of LOC554202 and miR-31 are associated with specific tissue regions of the colorectal area requires further investigation.

Although the majority of studies have concentrated on the expression analysis of miRNA-31 in clinical samples, few studies have demonstrated a plausible mechanism by which these effects are mediated. Tazawa et al showed that no induction of miR-34 was noted in $\mathrm{p} 53^{-/-}$cells following treatment with DNA-damaging agent Adriamycin (15). This tumor suppressive role was promoted via the E2F1 and E2F3 
proteins and was independent of apoptosis and caspase 3 activation (15).

It is important to note that the control of the expression of miR-31 and its host gene LOC554202 may be attributed to epigenetic regulation via mechanisms involving methylation and/or acetylation. It has been shown that the proximal $\mathrm{CpG}$ islands located within the promoter or 5' untranslated regions of miRNAs can epigenetically silence gene expression through DNA hypermethylation (48). Previous studies have demonstrated that certain miRNA genes with their corresponding host genes (hsa-mir-10a/HOXB4, hsa-mir-126/EGFL7, hsa-mir-152/COPZ2, hsa-mir-191/ $D A L R D 3$, and $h s a-m i r-342 / E V L)$ were found to be epigenetically downregulated, and/or silenced either by histone modification and/or $\mathrm{CpG}$ island hypermethylation in the promoter region in cancer cells (48). Methylated mir-155, mir-152, mir-137, and mir-31 host genes are considered as promising diagnostic and/or prognostic biomarkers of prostate cancer, whereas the methylation status of particular miRNA host genes as independent variables and/or in combinations may assist in the prediction of poor prognosis in patients with prostate cancer preoperatively (49). With regard to miR-31, it has been shown that promoter methylation was predictive of biochemical prostate cancer recurrent survival rate (49). This suggests that the silencing of this gene can affect its expression and corresponding function with regard to cancer development (49). In addition, Augoff et al demonstrated that loss of miR-31 expression in triple negative breast cancer cell lines was attributed to hypermethylation of its promoter-associated $\mathrm{CpG}$ island (5). Further investigations on the epigenetic regulation of miRNA/genes, including miR-31, may reveal novel approaches for the prevention or treatment of human cancer. Similarly, the contribution of miR-31 polymorphisms to the survival rates of patients with CRC cannot be ruled out and requires investigation in future investigations. To date, polymorphisms of miR-31 have been described in the involvement of this RNA in the regulation of angiotensinogen expression and body fat distribution (50). The miR-31 rs13283671 polymorphism was previously described in lung cancer, although it was not correlated with survival rate and/or certain clinicopathological parameters (51).

The findings of the present study may initially appear contradictory to the general hypothesis that a high expression of miR-31 contributes to CCR development. LOC554202 is an lncRNA, reported to be expressed at a high level in breast cancer and associated with advanced pathologic stage and tumor size (19). However, in CRC cells, LOC554202 has a tumor suppressor role in the activation of specific caspase cleavage cascades, and low expression of LOC554202 was associated with advanced pathologic stage and increased tumor size (32). miR-31 is a widely investigated miRNA and studies have reported controversial conclusions regarding its role in CRC cells (52-56). These studies suggest that a high expression of this miRNA in cancer does not always result in a decreased tumor growth, including that noted in cases of the oncosuppressors p53 and phosphatase and tensin homolog. In the present study, it was found that LOC554202 and miR-31 were expressed at high levels in oxaliplatin-treated CRC specimens, and their higher expression predicted optimal outcomes. As double-edged genes, the high expression levels of LOC554202 and miR-31 may be a responsive adaptation to oxaliplatin treatment. Investigations of the underlying mechanism of LOC554202 and miR-31 in oxaliplatin-treated CRC are ongoing.

Previously published studies have produced contradictory results with regard to the application of plasma levels of miR-31. It has been shown that miR-31 levels in plasma are upregulated in patients with CRC compared with healthy subjects, and that clinical analysis of the expression of miR-31 in patients with colon cancer may facilitate the diagnosis of colon cancer (57). By contrast, Jo et al investigated the miR profiles of plasma from patients with rectal cancer during chemoradiotherapy and found that plasma miRNA expression levels did not necessarily represent the miRNA expression levels in tumor tissues (58). This indicates that plasma miRs cannot be used with certainty for prognosis as their expression may be different with that in tumor tissues. Therefore, further investigations are required to validate their application as potential biomarkers in human plasma. The mechanism underlying the interaction between miR-31 and LOC554202 was not examined in the present study and warrants further investigation in the future. Evidence in the literature remains limited, and no information exists, to the best of our knowledge, with regard to CRC. A previous study revealed an association with the oncogene RNF144B in chordoma. Specifically, EZH2, a binding protein of LOC554202, was positively regulated by LOC554202, leading to the reduced expression of miR-31 (59). Furthermore, the impaired function of miR-31 restored expression of the RNF144B oncogene and maintained the metastasis-promoting activity in vitro (59). These results were also shown in vivo (59). This mechanism requires investigation in CRC in the future.

The present study had several limitations. The sample size of the study was small, and the nature of the study was retrospective. Further prospective studies are required to confirm the prediction efficiency of miR-31 and LOC554202. In addition, functional in vitro assays can provide insight into the mechanism of action of LOC554202 in CRC. The implication of LOC554202 in cancer metastasis can be examined, as it has been shown that miR-31 contributes to the invasion and migration of CRC cells by the miR-31/factor-inhibiting hypoxia-inducible factor 1 nexus (60). Loss of function and gain of function experiments can determine whether the expression of LOC554202 that is regulated by miR-31 is responsible for cancer invasion. In addition, a meta-analysis is likely to be a significant addition to this line of investigation in examining the expression of miR-31 and LOC554202 in CRC. However, the studies cited above contain significant heterogeneity for inclusion in a preliminary meta-analysis. This may be examined in a separate report to include a careful selection of studies with similar parameters for investigation, so as to minimize bias.

In conclusion, miR-31 and its homologous host gene LOC554202 were expressed at high levels and positively correlated with CRC prognosis. The increased expression of the latter RNA sequences prolonged the survival rate of patients with CRC, notably those with colon cancer. miR-31 and LOC554202 may be potential markers for the evaluation of the prognosis of postoperative patients treated with oxaliplatin-based chemotherapy. In vivo and in vitro assays, 
and a large randomized controlled trial with a large sample size are warranted to further elucidate the roles of LOC554202 and miR-31 in CRC.

\section{Acknowledgements}

We gratefully appreciate the efforts and contributions of doctors, nurses and technical staff at the First Hospital of China Medical University.

\section{Funding}

The present study was supported in part by a grant from the Liaoning Province Education Department Foundation (nos. LS201617 and LK201646).

\section{Availability of data and materials}

The datasets used during the present study are available from the corresponding author upon reasonable request.

\section{Authors' contributions}

YL participated in the literature search, designed the study, collected the data, analysed and interpreted the data and wrote the manuscript. SX participated in the design of the and provided the critical revision. $\mathrm{HW}, \mathrm{CX}, \mathrm{LD}, \mathrm{WS}, \mathrm{XH}, \mathrm{RL}$ and FZ carried out the data collection and data analysis, and provided the critical revision. All authors read and approved the final manuscript and agree to be accountable for all aspects of the research in ensuring that the accuracy or integrity of any part of the work are appropriately investigated and resolved.

\section{Ethics approval and consent to participate}

The present study was approved by the Medical Ethics Committee of the China Medical University at the First Hospital of China Medical University. Written informed consent was required by the patients for their participation in the study, as requested by the ethical guidelines of the First Hospital of China Medical University and the Medical Ethics Committee of the Chinese Medical Universities. All patients were anonymized.

\section{Patient consent for publication}

Not applicable.

\section{Competing interests}

The authors state that they have no competing interests.

\section{References}

1. Ferlay J, Shin HR, Bray F, Forman D, Mathers C and Parkin DM: Estimates of worldwide burden of cancer in 2008: GLOBOCAN 2008. Int J Cancer 127: 2893-2917, 2010.

2. Siegel R, Naishadham D and Jemal A: Cancer statistics, 2013. CA Cancer J Clin 63: 11-30, 2013.

3. Siegel R, Desantis C and Jemal A: Colorectal cancer statistics, 2014. CA Cancer J Clin 64: 104-117, 2014.

4. Chen W, Zheng R, Zeng H, Zhang S and He J: Annual report on status of cancer in China, 2011. Chin J Cancer Res 27: 2-12, 2015.
5. Augoff K, McCue B, Plow EF and Sossey-Alaoui K: miR-31 and its host gene lncRNA LOC554202 are regulated by promoter hypermethylation in triple-negative breast cancer. Mol Cancer 11: 5, 2012.

6. He L, Thomson JM, Hemann MT, Hernando-Monge E, Mu D, Goodson S, Powers S, Cordon-Cardo C, Lowe SW, Hannon GJ, et al: A microRNA polycistron as a potential human oncogene. Nature 435: 828-833, 2005.

7. Esquela-Kerscher A and Slack FJ: Oncomirs-microRNAs with a role in cancer. Nat Rev Cancer 6: 259-269, 2006.

8. Slaby O, Svoboda M, Fabian P, Smerdova T, Knoflickova D, Bednarikova M, Nenutil R and Vyzula R: Altered expression of miR-21, miR-31, miR-143 and miR-145 is related to clinicopathologic features of colorectal cancer. Oncology 72: 397-402, 2007.

9. Nosho K, Igarashi H, Nojima M, Ito M, Maruyama R, Yoshii S, Naito T, Sukawa Y, Mikami M, Sumioka W, et al: Association of microRNA-31 with BRAF mutation, colorectal cancer survival and serrated pathway. Carcinogenesis 35: 776-783, 2014.

10. Corcoran DL, Pandit KV, Gordon B, Bhattacharjee A, Kaminski N and Benos PV: Features of mammalian microRNA promoters emerge from polymerase II chromatin immunoprecipitation data. PLoS One 4: e5279, 2009.

11. Spizzo R, Almeida MI, Colombatti A and Calin GA: Long non-coding RNAs and cancer: A new frontier of translational research? Oncogene 31: 4577-4587, 2012.

12. Yao Y, Li J and Wang L: Large intervening non-coding RNA HOTAIR is an indicator of poor prognosis and a therapeutic target in human cancers. Int J Mol Sci 15: 18985-18999, 2014.

13. Luo M, Li Z, Wang W, Zeng Y, Liu Z and Qiu J: Long non-coding RNA H19 increases bladder cancer metastasis by associating with EZH2 and inhibiting E-cadherin expression. Cancer Lett 333: 213-221, 2013.

14. Zhao XL, Zhao ZH, Xu WC, Hou JQ and Du XY: Increased expression of SPRY4-IT1 predicts poor prognosis and promotes tumor growth and metastasis in bladder cancer. Int J Clin Exp Pathol 8: 1954-1960, 2015.

15. Tazawa $H$, Tsuchiya $N$, Izumiya $M$ and Nakagama $H$ : Tumor-suppressive miR-34a induces senescence-like growth arrest through modulation of the E2F pathway in human colon cancer cells. Proc Natl Acad Sci USA 104: 15472-14477, 2007.

16. Xi Y, Shalgi R, Fodstad O, Pilpel Y and Ju J: Differentially regulated micro-RNAs and actively translated messenger RNA transcripts by tumor suppressor p53 in colon cancer. Clin Cancer Res 12: 2014-2024, 2006.

17. Bandres E, Cubedo E, Agirre X, Malumbres R, Zarate R, Ramirez N, Abajo A, Navarro A, Moreno I, Monzó M, et al: Identification by real-time PCR of 13 mature microRNAs differentially expressed in colorectal cancer and non-tumoral tissues. Mol Cancer 5: 29, 2006.

18. Baskerville S and Bartel DP: Microarray profiling of microRNAs reveals frequent coexpression with neighboring miRNAs and host genes. RNA 11: 241-247, 2005.

19. Shi Y, Lu J, Zhou J, Tan X, He Y, Ding J, Tian Y, Wang L and Wang K: Long non-coding RNA Loc554202 regulates proliferation and migration in breast cancer cells. Biochem Biophys Res Commun 446: 448-453, 2014.

20. Schee K, Boye K, Abrahamsen TW, Fodstad O and Flatmark K: Clinical relevance of microRNA miR-21, miR-31, miR-92a, miR-101, miR-106a and miR-145 in colorectal cancer. BMC Cancer 12: 505, 2012.

21. Yang L, Wei H and Xiao HJ: Long non-coding RNA Loc554202 expression as a prognostic factor in patients with colorectal cancer. Eur Rev Med Pharmacol Sci 20: 4243-4247, 2016.

22. Xi S, Yang M, Tao Y, Xu H, Shan J, Inchauste S, Zhang M, Mercedes L, Hong JA, Rao M, et al: Cigarette smoke induces C/EBP- $\beta$-mediated activation of miR-31 in normal human respiratory epithelia and lung cancer cells. PLoS One 5: e13764, 2010.

23. Yang MH, Yu J, Chen N, Wang XY, Liu XY, Wang S and Ding YQ: Elevated microRNA-31 expression regulates colorectal cancer progression by repressing its target gene SATB2. PLoS One 8: e85353, 2013.

24. Dindo D, Demartines N and Clavien PA: Classification of surgical complications: A new proposal with evaluation in a cohort of 6336 patients and results of a survey. Ann Surg 240: 205-213, 2004.

25. Wang F, Flanagan J, Su N, Wang LC, Bui S, Nielson A, Wu X, Vo HT, Ma XJ and Luo Y: RNAscope: A novel in situ RNA analysis platform for formalin-fixed, paraffin-embedded tissues. J Mol Diagn 14: 22-29, 2012. 
26. Yeo W, Chan SL, Mo FK, Chu CM, Hui JW, Tong JH, Chan AW, Koh J, Hui EP, Loong H, et al: Phase I/II study of temsirolimus for patients with unresectable Hepatocellular Carcinoma (HCC)- a correlative study to explore potential biomarkers for response. BMC Cancer 15: 395, 2015.

27. Azim HA Jr, Peccatori FA, Brohee S, Branstetter D, Loi S, Viale G, Piccart M, Dougall WC, Pruneri G and Sotiriou C: RANK-ligand (RANKL) expression in young breast cancer patients and during pregnancy. Breast Cancer Res 17: 24, 2015.

28. Li SC, Tang P and Lin WC: Intronic microRNA: discovery and biological implications. DNA Cell Biol 26: 195-207, 2007.

29. Chen Y and Gorski DH: Regulation of angiogenesis through a microRNA (miR-130a) that down-regulates antiangiogenic homeobox genes GAX and HOXA5. Blood 111: 1217-1226, 2008.

30. Yi R, Pasolli HA, Landthaler M, Hafner M, Ojo T, Sheridan R, Sander C, O'Carroll D, Stoffel M, Tuschl T, et al: DGCR8-dependent microRNA biogenesis is essential for skin development. Proc Natl Acad Sci USA 106: 498-502, 2009.

31. Ozsolak F, Poling LL, Wang Z, Liu H, Liu XS, Roeder RG, Zhang X, Song JS and Fisher DE: Chromatin structure analyses identify miRNA promoters. Genes Dev 22: 3172-3183, 2008.

32. Ding J, Lu B, Wang J, Wang J, Shi Y, Lian Y,Zhu Y, Wang J, Fan Y, Wang Z, et al: Long non-coding RNA Loc554202 induces apoptosis in colorectal cancer cells via the caspase cleavage cascades. J Exp Clin Cancer Res 34: 100, 2015.

33. Luo LJ, Yang F, Ding JJ, Yan DL, Wang DD, Yang SJ, Ding L, Li J, Chen D, Ma R, et al: MiR-31 inhibits migration and invasion by targeting SATB2 in triple negative breast cancer. Gene 594: $47-58,2016$.

34. Wang H, Zhang X, Liu Y, Ni Z, Lin Y, Duan Z, Shi Y, Wang G and Li F: Downregulated miR-31 level associates with poor prognosis of gastric cancer and its restoration suppresses tumor cell malignant phenotypes by inhibiting E2F2. Oncotarget 7: 36577-36589, 2016.

35. Du Z, Niu S, Xu X and Xu Q: MicroRNA31-NDRG3 regulation axes are essential for hepatocellular carcinoma survival and drug resistance. Cancer Biomark 19: 221-230, 2017.

36. Wang CJ, Zhou ZG, Wang L, Yang L, Zhou B, Gu J, Chen HY and Sun XF: Clinicopathological significance of microRNA-31, -143 and -145 expression in colorectal cancer. Dis Markers 26: 27-34, 2009.

37. Sun Y, Jin L, Liu JH, Sui YX, Han LL and Shen XL: Interfering $\mathrm{EZH} 2$ expression reverses the cisplatin resistance in human ovarian cancer by inhibiting autophagy. Cancer Biother Radiopharm 31: 246-252, 2016.

38. Zhou W, Wang J, Man WY, Zhang QW and Xu WG: siRNA silencing EZH2 reverses cisplatin-resistance of human non-small cell lung and gastric cancer cells. Asian Pac J Cancer Prev 16: 2425-2430, 2015.

39. Hu S, Yu L, Li Z, Shen Y, Wang J and Cai J: Overexpression of EZH2 contributes to acquired cisplatin resistance in ovarian cancer cells in vitro and in vivo. Cancer Biol Ther 10: 788-795, 2010.

40. Li M, Chen W, Zhang H, Zhang Y, Ke F, Wu X, Zhang Y, Weng M, Liu Y and Gong W: MiR-31 regulates the cisplatin resistance by targeting Src in gallbladder cancer. Oncotarget 7: 83060-83070, 2016.

41. Ayiomamitis GD, Notas G, Zaravinos A, Zizi-Sermpetzoglou A, Georgiadou M, Sfakianaki O and Kouroumallis E: Differences in telomerase activity between colon and rectal cancer. Can J Surg 57: 199-208, 2014.

42. Wen L, Cheng F, Zhou Y and Yin C: MiR-26a enhances the sensitivity of gastric cancer cells to cisplatin by targeting NRAS and E2F2. Saudi J Gastroenterol 21: 313-319, 2015.

43. Liu H, Li W, Yu X, Gao F, Duan Z, Ma X, Tan S, Yuan Y, Liu L, Wang J, et al: EZH2-mediated Puma gene repression regulates non-small cell lung cancer cell proliferation and cisplatin-induced apoptosis. Oncotarget 7: 56338-56354, 2016.
44. Cai L, Wang Z and Liu D: Interference with endogenous EZH2 reverses the chemotherapy drug resistance in cervical cancer cells partly by up-regulating Dicer expression. Tumour Biol 37: 6359-6369, 2016.

45. Zhang Q, Padi SK, Tindall DJ and Guo B: Polycomb protein EZH2 suppresses apoptosis by silencing the proapoptotic miR-31. Cell Death Dis 5: e1486, 2014.

46. Ito M, Mitsuhashi K, Igarashi H, Nosho K, Naito T, Yoshii S, Takahashi H, Fujita M, Sukawa Y, Yamamoto E, et al: MicroRNA-31 expression in relation to $B R A F$ mutation, $\mathrm{CpG}$ island methylation and colorectal continuum in serrated lesions. Int J Cancer 135: 2507-2515, 2014.

47. Zhong Z, Dong Z, Yang L, Chen X and Gong Z: MicroRNA-31-5p modulates cell cycle by targeting human mutL homolog 1 in human cancer cells. Tumour Biol 34: 1959-1965, 2013.

48. Godnic I, Zorc M, Jevsinek Skok D, Calin GA, Horvat S, Dove P, Kovac M and Kunej T: Genome-wide and species-wide in silico screening for intragenic MicroRNAs in human, mouse and chicken. PLoS One 8: e65165, 2013.

49. Daniunaite K, Dubikaityte M, Gibas P, Bakavicius A, Rimantas Lazutka J, Ulys A, Jankevicius F and Jarmalaite S: Clinical significance of miRNA host gene promoter methylation in prostate cancer. Hum Mol Genet 26: 2451-2461, 2017.

50. Machal J, Novak J, Hezova R, Zlamal F, Vasku A, Slaby O and Bienertova-Vasku J: Polymorphism in miR-31 and miR-584 binding site in the angiotensinogen gene differentially influences body fat distribution in both sexes. Genes Nutr 10: 488, 2015

51. Chen Z, Xu L, Ye X, Shen S, Li Z, Niu X and Lu S: Polymorphisms of microRNA sequences or binding sites and lung cancer: A meta-analysis and systematic review. PLoS One 8: e61008, 2013.

52. Tateishi Y, Okudela K, Mitsui H, Umeda S, Suzuki T, Kojima Y, Watanabe K, Kawano N, Endo I and Ohashi K: The potential role of microRNA-31 expression in early colorectal cancer. Pathol Int 65: 513-518, 2015.

53. Carames C, Cristobal I, Moreno V, Marin JP, Gonzalez-Alonso P, Torrejon B, Minguez P, Leon A, Martín JI, Hernández R, et al: MicroRNA-31 Emerges as a predictive biomarker of pathological response and outcome in locally advanced rectal cancer. Int J Mol Sci 17: pii: E878, 2016.

54. Yang X, Xu X, Zhu J, Zhang S, Wu Y, Wu Y, Zhao K, Xing C, Cao J, Zhu H, et al: miR-31 affects colorectal cancer cells by inhibiting autophagy in cancer-associated fibroblasts. Oncotarget 7: 79617-79628, 2016.

55. Liu Z, Bai J,Zhang L, Lou F, Ke F, Cai W and Wang H: Conditional knockout of microRNA-31 promotes the development of colitis associated cancer. Biochem Biophys Res Commun 490: 62-68, 2017.

56. Tian Y, Ma X, Lv C, Sheng X, Li X, Zhao R, Song Y, Andl T, Plikus MV, Sun J, et al: Stress responsive miR-31 is a major modulator of mouse intestinal stem cells during regeneration and tumorigenesis. Elife 6: pii: e29538, 2017.

57. Wang YN, Chen ZH and Chen WC: Novel circulating microRNAs expression profile in colon cancer: A pilot study. Eur J Med Res 22: 51, 2017.

58. Jo P, Azizian A, Salendo J, Kramer F, Bernhardt M, Wolff HA, Gruber J, Grade M, Beißbarth T, Ghadimi BM and Gaedcke J: Changes of microrna levels in plasma of patients with rectal cancer during chemoradiotherapy. Int J Mol Sci 18: pii: E1140, 2017.

59. Ma X, Qi S, Duan Z, Liao H, Yang B, Wang W, Tan J, Li Q and Xia X: Long non-coding RNA LOC554202 modulates chordoma cell proliferation and invasion by recruiting EZH2 and regulating miR-31 expression. Cell Prolif 50, 2017.

60. Chen T, Yao LQ, Shi Q, Ren Z, Ye LC, Xu JM, Zhou PH and Zhong YS: MicroRNA-31 contributes to colorectal cancer development by targeting factor inhibiting HIF-1alpha (FIH-1). Cancer Biol Ther 15: 516-523, 2014. 